\title{
RAILWAY BRIDGE STRUCTURAL HEALTH MONITORING AND FAULT DETECTION: STATE-OF-THE-ART METHODS AND FUTURE CHALLENGES
}

\author{
Matteo Vagnoli ${ }^{1 *}$, Rasa Remenyte-Prescott ${ }^{1}$, John Andrews $^{1}$ \\ ${ }^{1}$ Resilience Engineering Research Group, the University of Nottingham \\ Science Road, University Park, \\ NG7 2RD, Nottingham, United Kingdom \\ *Corresponding author: Matteo.vagnoli@nottingham.ac.uk
}

\begin{abstract}
Railway importance in the transportation industry is increasing continuously, due to the growing demand of both passenger travel and transportation of goods. However, more than $35 \%$ of the 300,000 railway bridges across Europe are over 100 years old, and their reliability directly impacts the reliability of the railway network. This increased demand may lead to higher risk associated to their unexpected failures, resulting safety hazards to passengers and increased whole life cycle cost of the asset. Consequently, one of the most important aspects of evaluation of the reliability of the overall railway transport system is bridge Structural Health Monitoring (SHM), which can monitor the health state of the bridge by allowing an early detection of failures. Therefore, a fast, safe and cost-effective recovery of the optimal health state of the bridge, where the levels of element degradation or failure are maintained efficiently, can be achieved. In this paper, after an introduction to the desired features of SHM, a review of the most commonly adopted bridge fault detection methods is presented. Mainly, the analysis focuses on model-based Finite Element (FE) updating strategies, non-modelbased (data-driven) fault detection methods such as Artificial Neural Network (ANN), and Bayesian Belief Network (BBN)-based SHM methods. A comparative study, which aims to discuss and compare the performance of the reviewed types of SHM methods, is then presented by analysing a short-span steel structure of a railway bridge. Opportunities and future challenges of the fault detection methods of railway bridges are highlighted.
\end{abstract}

Keywords: Structural Health Monitoring (SHM); Railway bridges; fault detection and diagnosis; Artificial Neural Network; Finite element model updating; Future challenges. 


\section{Introduction}

In the last decades, the railway infrastructure has expanded in many countries due to the increase in trains capacity in terms of rail passengers and goods (for example, in the UK the number of passengers has doubled in the last twenty years [ORR, 2015]). As railways are exposed to various external loads, such as traffic and environment, the transport safety risk and the whole life cost of railway assets increase due to this new demand of performance [Lee et al., 2005; Chattopadhyay et al., 2007; Sharma et al., 2014]. Bridges are a vital element of the transport infrastructure, for example, across Europe there are more than 300,000 railway bridges for 212,000 km of railway [Tantele et al., 2010; European Commission, 2012]. More than $35 \%$ of these bridges are over 100 years old and, thus, this ageing infrastructure poses a high risk to the overall availability of the railway network. This is due to the fact that in order to improve railway capacity, railway bridges, especially, old bridges, are being pushed to their physical limit, due to increased transfer speed, axle load, train frequency and length [Elfgren et al., 2008; Reyer et al., 2011; Le et al., 2013; Pipinato et al., 2016].

In addition, bridges are comprised of relatively small elements, such as beams, deck slab and abutments, which are subject to deterioration process that could lead to a reduced level of service and, potentially, to a lower safety level of the whole bridge structure [Phares et al., 2001; Gangone et al., 2011; Rafiq et al., 2015]. Therefore, one of the critical aspects of railway infrastructure availability analysis is bridge condition assessment, known as Structural Health Monitoring (SHM) [Doebling et al., 1998; Chase et al., 2001]. SHM methods are used to accurately assess the health state of bridges, which are largely evaluated by visual inspections at regular intervals, such as from one to six years. More detailed examination and analysis using localized non-destructive evaluation techniques, such as radio X-ray, radiographic, eddy current and ultrasonic method, are then performed, if necessary, at the degraded location, which has been identified during the visual inspection [Yeung et al., 2005; Ignat-Coman et al., 2008; CDT, 2012]. Indeed, localized non-destructive methods require that the fault location is known a priori; consequently, the part of the structure under inspection needs to be accessible and no train service is possible during the inspection [Doebling et al., 1998; Wang et al., 2009]. Also, during a visual inspection the structure is examined intermittently and some faults might not be detected (for example, truss bridges experience unavoidable micro-cracks, which occur during the welding of joints, and which may not be observed during visual inspection) [Chan et al., 2001; Chase, 2004]. Furthermore, the visual inspection can be time-consuming, costly and, therefore, infrequent, and since it is based on expert knowledge the outcomes can be significantly variable in terms of structural condition assessment, due to subjectivity of the assessor [Phares et al., 2004; Stajano et al., 2010].

In order to overcome the limitations of visual inspections, the SHM methods, based on mathematical and statistical approaches, have become an increasingly important technology used during the identification and isolation of faults, through the analysis of static and dynamic responses of civil infrastructure (including bridges) to environmental conditions or vehicle loads [Ou, 2003; Lynch et al., 2006]. In addition, as railway bridges are expensive to maintain and critical asset of the railway network, their maintenance process has a large impact on their whole life cycle cost, and the SHM methods can be used to find an optimal maintenance 
schedule [Webb et al., 2015; Zhao et al., 2015]. For these reasons, several SHM studies on bridge elements have been developed in the last decades, which have been thoroughly reviewed by several authors [Doebling et al., 1996; Doebling et al., 1998; Carden et al., 2004; Wang et al., 2009; Fan et al., 2011]. In these publications, the SHM methods are categorized based on the nature of their input data, i.e. relying on the type of the measured structural vibration response changes, such as change in modal frequencies, measured mode shapes (and their derivatives) and flexibility coefficients. [Doebling et al., 1996] and [Doebling et al., 1998] present a classification of the SHM methods, which has been then adopted by other authors [Carden et al., 2004; Wang et al., 2009; Fan et al., 2011], by mainly categorizing the methods into four classes depending on the nature of the analysed structural vibration response changes: i) frequency change; ii) mode shape; $i i i)$ mode shape curvature/strain mode shape change; iv) dynamically measured flexibility. The SHM methods, which are based on the Finite Element (FE) model updating strategies and Artificial Neural Network (ANN), are only briefly described. Generally, the conclusion of the review papers mentioned above is that there are still some challenges to be addressed in detecting failure by using modal response of the bridge due to the fact that the measurements are influenced by noise, and furthermore, fault detection methods have mainly shown good performance only in controlled laboratory conditions. When monitoring the performance of a real bridge, it is difficult to distinguish between shifts of the modal parameters caused by the deterioration of the structure, those occurring due to the statistical variability of the measurements and those caused by changing environmental conditions. For example, [Kim et al., 2007] discussed that the natural frequencies of a healthy bridge (i.e. a bridge without any damage) decrease as the air temperature increases, and [Santos et al., 2016] presented a Neural Network in order to simulate and predict the structural behaviour of a bridge by using the air temperature as an input to the network. It is thus important to embed the changes of the environmental conditions (such as climate, traffic load and degradation mechanisms) in the SHM analysis of the bridge [He et al., 2008; Xie et al., 2011], and the development of fault detection methods that are appropriate to in-field applications is desiderable [Doebling et al., 1996; Doebling et al., 1998; Carden et al., 2004; Wang et al., 2009; Fan et al., 2011].

Another type of classification for the SHM methods is in terms of differences between modelbased and non-model-based reasoning [Doebling et al., 1998]. A model-based method detects faults by using a mathematical model of the bridge, which describes the physical laws of the structural behaviour using the systematic knowledge of the engineers, who are expert in bridge design. The differences between the actual structural behaviour, which can be determined by in-field measurements, and the expected structural behaviour, which is determined by the mathematical model, are used to assess the health state of the system. These methods can find the fault location, severity and possible fault evolution; however, a lot of measurements, and their detailed processing, are needed to build an accurate model, jeopardizing the potential of an online fault detection process of structures. On the other hand, non-model-based methods, generally more appropriate for the detection of the fault location but not for the estimation of fault magnitude, derive behavioural models for analysing the health condition using the measured data directly, and the faults are detected relying on the analysis of the monitored data. In the latter case, the models can be completely disconnected from the real physical structural behaviour of the infrastructure, i.e. the fault detection methods rely on the mathematical 
(statistical) analysis of the bridge behaviour rather than on the comparison between the simulated and actual bridge behaviour [Venkatasubramanian et al., 2003a; Venkatasubramanian et al., 2003b; Lampis et al., 2009; Kan et al., 2015; Sanayei et al., 2015]. In this paper, an introduction to the desiderata concept of the SHM is given, and then, a review of SHM methods for bridges is presented. However, instead of following one of the schemes proposed by [Doebling et al., 1996], the review is carried out by classifying the methods following their mathematical nature: $i$ ) model-based methods based on the FE updating strategy; ii) non-model-based methods, such as ANN methods, which are one of the most developed SHM methods fault detection methods and Bayesian Belief Network (BBN) methods. As a railway network is not as flexible as a road network, where the latter usually contains a number of alternative routes, a service interruption due to railway bridge closure can be very critical [Chen et al., 1999], and consequently a robust and reliable SHM for a railway bridge is of great importance in order to minimise such interruptions. It is also worth mentioning that even when the SHM techniques are more commonly implemented on highway bridges, rather than railway bridges, especially in cases of to high-speed railway bridges [Ding et al., 2015], this paper focusses on the review of condition monitoring and fault detection methods that are applied to railway bridges. However, in order to explain some of the methods that can be adopted on a bridge structure, examples of the SHM methods that were applied to highway bridges, especially in the area of FE modelling, are also presented, as there is a large number of such examples in literature. It is worth noting that the analysis of the case studies on highway bridges in this paper aims to describe the basics of the method and its performance with respect to the desiderata of an SHM method. Furthermore, an SHM method, which is developed and tested on a particular case study, can be then applied to different case studies by adapting the parameters of the SHM method to the behaviour and environmental conditions that are found in a particular case study. This adoption process can be easier for a non-modelbased method than a model-based method, as the non-model-based method can be used to assess the health state of any type of bridge, railway or highway, by monitoring the measured data directly, whereas, the model-based SHM method requires the development of a detailed mathematical model of a particular type of bridge. Therefore, although both types of bridges are considered in order to discuss some SHM methods, the emphasis is placed on railway bridge health monitoring and fault detection. Finally, the future research challenges and industry needs are discussed.

The paper is organized as follows: the desiderata of SHM are discussed in Section 2; Section 3 introduces the literature review discussion; opportunities and future challenges are discussed in Section 4; conclusions and final remarks are provided in Section 5.

\section{Structural Health Monitoring desiderata}

According to the definition of SHM given by [Andersen et al., 2006], "Structural Health Monitoring (SHM) aims to give, at every moment during the life of a structure, a diagnosis of the "state" of the constituent materials, of the different parts, and of the full assembly of these parts constituting the structure as a whole", different bridge elements, such as, beams, deck slab, abutments, etc., influence the health state of the whole bridge and thus the health state of 
each element should be assessed simultaneously. Following this definition, the desiderata of the SHM can be given as follows, by describing the main goal of achieving a real-time monitoring capability followed by a description of each step necessary to achieve this goal:

- Real-time monitoring of the structure. In order to achieve a continuous SHM (that is, "at every moment during the life of a structure, a diagnosis of the "state" [Andersen et al., 2006]), a continuous flow of data, which measures changes in the behaviour of the monitored bridge, is needed [Yeung et al., 2005; Nair et al., 2010]. Indeed, continuous SHM methods are desirable in the railway bridge framework, because an early identification of possible bridge failure can be achieved using continuous health monitoring and condition assessment strategies [Sekuła et al., 2012]. Therefore, necessary maintenance and repair works can start as soon as early signs of failure are identified, and consequently a reduction of the direct life cost of the bridge can be achieved [Adey et al., 2004; Yi et al., 2013; Chang et al., 2014]. Furthermore, railway bridge maintenance cost increases as the bridges get older. For these reasons, railway bridge owners require methods to prioritise the repair schedule and implement a condition-based maintenance strategy, by knowing the health state of the bridge in realtime [Nielsen et al., 2013].

- Choice of the type of sensors. The monitoring system needs to supply reliable data about the structure, in order to efficiently and continuously monitor railway bridges and to predict their durability and remaining useful time [Krüger et al., 2006; Lédeczi et al., 2009]. It has already been demonstrated in literature that a hybrid and integrated sensor system, consisting of GPS receivers, accelerometers, strain gauges and weather stations, could greatly increase the accuracy and reliability of the overall monitoring system [Roberts et al., 2001; Roberts et al., 2004; Barnes et al., 2005; Moschas et al., 2011; Psimoulis et al., 2013; Han et al., 2015]. Indeed, traditionally a measurement system is based on only one type of sensors, such as strain gauges, accelerometers, tiltmeters, vision systems, optometers, fibre optic, piezoelectric sensors and GPS, which are used to measure bridge strain, displacement, acceleration, or rotation, instead of relying on a hybrid and integrated sensor system [Brown et al., 1999; Roberts et al., 2001; Roberts et al., 2004]. Finally, the measuring system should provide remote condition monitoring by continuously transmitting real-time data using networking technologies, such as wireless and mobile networking [Akyidiz et al., 2002; Laory et al., 2012; Hodge et al., 2015].

- A cost-effective monitoring system. In order to have a balance between the cost of the measuring system and the quality of the information that can be retrieved about the structure, sensors need to be installed on the most informative position, i.e. the location that provides the least uncertainty in the bridge parameter evaluations [Liu et al., 2008]. The sensor position is usually determined using expert knowledge; however, for a structure that has not been monitored before, it may be difficult to determine the optimal sensor location, based on the experience of bridge operators [Li et al., 2004]. Some studies have been proposed in order to find the best configuration of the measurement system, i.e. the appropriate number of sensors to be employed, and the optimal sensor placements, i.e. the most informative locations [Meo \& Zumpano, 2005; Azarbayejani 
et al., 2008; Liu et al., 2008; Laory et al., 2012]. Also, as the number of sensors increases, for example, on a large bridge, the process of finding the optimal measurement system configuration becomes more complex, and optimization techniques need to be applied [Azarbayejani et al., 2008].

- Mathematical methods for exhaustive SHM process. Once sensor data is transmitted through the communications network, it has to be then analysed by a mathematical method in order to automatically, remotely and rapidly assess the level of deterioration of the bridge, and consequently its health state, without having to send expensive inspection crews to the site [Soyoz et al., 2009]. The main objective of the SHM method is to detect and diagnose a failure during its early stage, so that the maintenance crew can go to the site, knowing the required level of maintenance or repair to be carried out, so that the service can be restored rapidly [Katipamula et al., 2005]. The ability to predict future possible failure of the bridge elements is also required by the method, in order to prevent undesired and unscheduled railway closure, which consequently improves the availability of the whole railway system. Basically, the SHM method need to meet all the four requirements of the fault detection process: $i$ ) identification of the failure existence; $i$ ) identification of the failure location; iii) identification of the failure magnitude and causes; $i v$ ) assessment of the residual useful life (RUL) of the structure [Wang et al., 2009]. This process should be based on the analysis of how the degradation mechanism of the bridge influences the bridge behaviour [Goodall et al., 2006; Sathananthan et al., 2010; Galar et al., 2013]. Furthermore, a preventive maintenance strategy can be adopted by knowing the probability of failure of the bridge and its components, and through an optimization process maintenance actions can be investigated, by considering their maintenance cost and probability of failure [Tantele et al., 2009]. Finally, it should be noted that the modal parameters of real bridges are strongly influenced by environmental changes (such as increase of air temperature), and therefore an optimal SHM method is required to be adaptive to environmental changes in order to detect only actual changes to the bridge health state, without activating false alarms due to changes in environmental conditions [Cao et al., 2011; Zhou \& Yi, 2014].

Graphically, the desiderata SHM procedure can be depicted as proposed Fig. 1. Bridge performance is influenced by environmental conditions, such as climate change and traffic load, which mainly influence the vibration properties of the bridge. Therefore, the variability of environmental conditions under current and future scenarios, e.g. climate and traffic scenarios, has to be considered in the SHM analysis. Therefore, once the bridge is stimulated by an external disturbance (such as passing train, wind, etc.), the response (behaviour) of the bridge is recorded by sensors, which are installed in the optimal position (after using an optimization method for the location analysis using, for example, the FE model of the bridge). Sensor data is then pre-processed in order to remove noise and any influence of changing environmental condition (for example, the collected data can be filtered out by eliminating such influence on the measured bridge behaviour). Then, processed data is used as input data to the SHM method, such as an FE model updating (where the initial FE model is based on the blueprint of the bridge and on the historical visual inspection reports) or a data-driven fault detection method. If the bridge is in a good condition, faults do not occur and the next set of 
measurements can be analysed. At the same time, a prediction model, based on both environmental and bridge behaviour data to assess, predict and simulate the degradation mechanism and the bridge behaviour, can be used in order to predict future expected health state of the bridge. On the contrary, if a fault is detected during the fault detection process, which is the first step of fault analysis evaluation, fault diagnostic analysis has to be performed. During the fault diagnostic step, level two and level three of fault analysis evaluation are investigated, through the assessment of the fault location and fault severity, respectively. Once the characteristic of the failure are identified (i.e. the failure presence, location and severity), the RUL, during which the bridge can be safely used, has to be assessed. In the case when the fault on the bridge is particularly severe and, thus, the safety of the bridge is compromised, a safety alarm is raised, and maintenance crews are sent to the site in order to repair the bridge fault and restore the bridge safety as soon as possible. On the other hand, if the safety of the bridge is still within an acceptable level of risk, a condition-based maintenance strategy can be evaluated by optimizing the time-intervention of the maintenance, based on the health state of the element of the structure and on the cost of the maintenance activities.

It is worth emphasizing the desirable characteristics of the SHM method. The SHM method should detect faults and diagnose failures quickly, it should be able to distinguish between different failures, being robust to measurement noise and data uncertainties. Finally, it should be able to identify whether the behaviour is normal or abnormal, and if it is abnormal, whether its cause is known or unknown [Venkatasubramanian et al., 2003; Zio, 2012]. The SHM method should be also able to handle both the epistemic uncertainty, which is due to incomplete knowledge of model parameters, and the aleatory uncertainty, which is a persistent randomness of system behaviour [Catbas et al., 2008]. These desirable characteristics can lead to assessing the fault existence, location and severity, and to determining the system residual useful life, which means that the fault analysis evaluation can performed at all four levels [Wang et al., 2009].

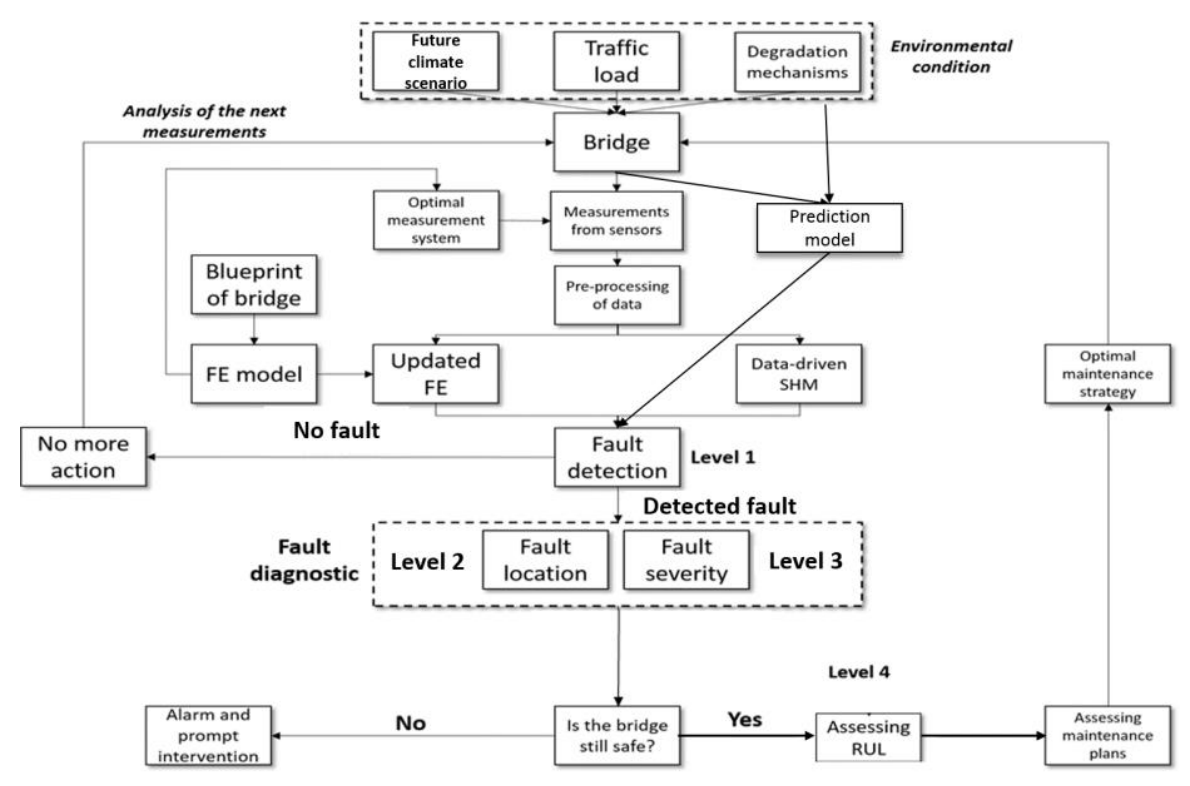

Fig. 1. Flowchart of SHM analysis. 


\section{Review of the current SHM methods}

In what follows, a brief review of the most commonly presented SHM methods is discussed. The methods are categorized based on their mathematical nature: model-based methods, such as FE model updating strategy model, which aim to detect the health state of the bridge by comparing the parameters of a mathematical model with those measured on the real structure, and non-model-based methods, which aim to assess the health state of the bridge by analysing the bridge behaviour without developing a model of the structure, but by only considering the analysis of the monitored data. This latter methods have been increasing developed in the last years due to their lower computational effort with respect to the FE model updating methods. ANN methods, which are one of the most developed non-model-based method, Probabilistic Neural Networks, machine learning and statistical methods, such as Support Vector Machine, Genetic Algorithm (GA), principal component analysis, and Bayesian regression, unsupervised fault detection techniques based on clustering algorithms and BBN methods are described in the non-model-based section. Limitations of each model with respect to the desiderata of the SHM are also discussed.

\subsection{Model-based fault detection methods}

A model-based fault detection method aims to assess the health state of the bridge by comparing the parameters of a mathematical model representing the monitored bridge, which is usually developed using Finite Element (FE) modelling techniques, with the responses measured by sensors on a real structure. FE models are used to analyse and predict the bridge behaviour under different environmental conditions due to their computational and modelling capacity. However, during the development of the FE model, many model parameters (such as material properties, geometric properties and boundary conditions) are unknown and, thus, several assumptions and simplifications need to be made [Mottershead \& Friswell, 1993]. Then, an updating technique of the FE bridge model is developed in order to merge the results of the FE analysis and the measurement of the real behaviour of the bridge. Indeed, the acquired experimental data (such as acceleration, natural frequencies, mode shape, displacements, etc.) provide comprehensive information regarding the global and local behaviour of the bridge and, thus, the initial FE model characteristics (both geometrical and physical), and its boundary conditions, can be updated. In this way, bridge responses provided by the FE model are being pushed to be as similar as possible to the real measured performance of a bridge, and the FE model accuracy is increased and model uncertainties reduced. FE updating strategies can be divided into local and global methods, based on the updating strategy of the system matrices (mass, stiffness and damping matrices). The former models are based on corrections, applied to local physical parameters of the FE model, whereas the latter models are based on the reconstruction of the updated global mass and stiffness matrices [Brownjohn et al., 2001; Schlune et al., 2009]. In what follows, a description of the theoretical background of the FE model updating is presented, followed by a review of some research papers, which are based 
on this technique. The literature review aims to explain the main ideas of the FE model updating technique, rather than being comprehensive of all the works presented in literature.

\subsubsection{Principles of the FE model updating}

The FE model updating problem, independently from the nature of the modelled structure, is an inverse problem, which aims to obtain the optimal model parameters, $\left(\vartheta^{*}\right)$, that produce a behaviour of the modelled structure as close as possible to that one of the real structure. Therefore, the assessment of the optimal set of the FE model parameters, $\left(\vartheta^{*}\right)$, is the objective of the updating process. Indeed, given the model output, $\left(y^{*}\right)$ and its input, $\left(x^{*}\right)$, these are correlated through a transfer operator, $(G)$, which is described by a set of model parameters ( $\vartheta)$ :

$$
y^{*}=G\left(x^{*}, \vartheta\right)
$$

The updating process searches for the optimal set of model parameters, $\left(\vartheta^{*}\right)$, in order to minimize the difference between the FE model and the experimental data, $(d)$ :

$$
\vartheta^{*}=\arg \min F\left(G\left(x^{*}, \vartheta\right), d\right)
$$

where $F$ is a cost function that has to be minimized.

The modal characteristics of the structure, i.e. natural frequencies, mode shape, etc., are usually used as experimental data $(d)$ for the FE model updating process. On the other hand, the time domain response data, such as acceleration, are not usually used, since they require the precise knowledge of the input excitation of the bridge and in many practical applications the input excitation is not known precisely [Brownjohn et al., 2001].

\subsubsection{Selection and updating of FE parameters}

The optimization problem, where the objective is to minimize the discrepancy between computed and measured data, may be ill-conditioned, i.e. the existence, uniqueness and stability (with respect to small errors) of a solution of the inverse problem cannot be guaranteed. A smart selection of the optimal set of model parameters, $\left(\vartheta^{*}\right)$, in order to avoid an illconditioned problem can be done, for example, through a sensitivity analysis process, which, furthermore, is usually adopted to update the optimal set of model parameters $\left(\vartheta^{*}\right)$ [Brownjohn et al., 2001; Simoen et al., 2015].

The sensitivity analysis procedure to find the optimal set of model parameters, $\left(\vartheta^{*}\right)$, can be developed as follows. The vectors of the experimental measured response (i.e. the modal response of the bridge, such as natural frequencies and mode shape), $\left(R_{e}\right)$, can be expressed as a first order Taylor series of the analytical response, $\left(R_{a}\right)$, i.e. the vectors of FE model response at the current iteration: 


$$
R_{e}=R_{a}+[S]\left(P_{u}-P_{o}\right)
$$

where $[S]$ is the sensitivity matrix, $P_{u}$ is the vector of updated parameter values and $P_{o}$ is the vector of current iterative parameter values.

The sensitivity matrix $[S]$ can be calculated as:

$$
[S]_{i j}=\frac{\partial R_{i}}{\partial P_{j}}
$$

where $R_{i}$ and $P_{j}$ represent the $i$-th component of the modal vector and the $j$-th component of the updating parameter vector, respectively.

Eq. (3) can be rewritten as:

$$
\Delta R=[S] \Delta P
$$

where $\Delta P$ is the perturbation of the updating parameters, which can be computed as:

$$
\Delta P=[S]^{*} \Delta R
$$

Here $\Delta R$ is the difference between the experimental and FE model response at the current iteration:

$$
\Delta R=R_{e}-R_{a}
$$

and $[S]^{*}$ is the pseudo-inverse matrix of the sensitivity matrix $[S]$ and it may be computed as:

$$
[S]^{*}=\left\{\begin{array}{lll}
{[S]^{-1}} & \text { if } & N=M \\
\left([S]^{T}[S]\right)^{-1}[S]^{T} & \text { if } & N>M \\
{[S]^{T}\left([S]^{T}[S]\right)^{-1}} & \text { if } & N<M
\end{array}\right.
$$

$M$ and $N$ represent the number of the updating parameters and the number of the observed bridge responses, respectively.

Usually, $M$ is greater than $N$ and a Bayesian estimation technique is adopted to compute the pseudo inverse matrix, $[S]^{*}$, of the sensitivity matrix, $[S]$, introducing the weighting matrix of the updating parameters, $\left(C_{p}\right)$, (i.e. the confidence level in model parameter value) and that of the measured modal data, $\left(C_{R}\right)$, (i.e. the confidence level in experimental measured response). In this case, the perturbation of the updating parameters can be assessed as [Ding \& Li, 2008]: 


$$
\Delta P=\left[C_{p}\right]^{-1}[S]^{T}\left(\left[C_{R}\right]^{-1}+[S]\left[C_{p}\right]^{-1}[S]^{T}\right)^{-1} \Delta R
$$

Finally, in order to achieve a fast and finite (i.e. not prone to divergence) updating procedure, the responses provided by the initial FE model need to be relatively similar to those provided by the real measured responses. On contrary, if large differences exist between the simulated and measured bridge responses, the iterative process may be divergent [Ding \& Li, 2008].

\subsubsection{FE model updating in fault detection}

The FE model updating strategies require the development of a detailed FE model of the bridge, in order to reproduce the real bridge behaviour. The development of the FE model can be complex, time-consuming and expensive. However, many authors have developed techniques to update FE bridge model, and due to the fact that the expected results provided by the FE model can be compared with the real data provided, a fault detection analysis can be carried out by assessing the difference between the behaviour of the real bridge and the one obtained from the FE model. In what follows, a description of FE updating strategies is provided in section 3.1.3.1, whereas coupling strategies between FE model updating and optimization algorithms, such as Genetic algorithms and ANN, is described in section 3.1.3.2.

\subsubsection{FE model updating examples}

In this section the FE model updating methods are described by pointing out the type of bridge that was analysed, the choice of the updating parameters and by describing the updating strategy. Finally, the results of each work are presented. Table 1 shows the information of the works presented in this section.

\begin{tabular}{|c|c|c|c|c|}
\hline Reference & Type of bridge & $\begin{array}{c}\text { Updating } \\
\text { parameter(s) }\end{array}$ & Updating strategy & Results \\
\hline Sanayei et al., 2015 & $\begin{array}{l}\text { Bridge model that } \\
\text { was designed as a } \\
\text { grid system. }\end{array}$ & $\begin{array}{l}\text { Bending rigidity, area } \\
\text { mass and boundary } \\
\text { link stiffness }\end{array}$ & $\begin{array}{l}\text { To minimize the error } \\
\text { function }\end{array}$ & $\begin{array}{l}\text { High correlation } \\
\text { between the } \\
\text { empirical and } \\
\text { analytical data }\end{array}$ \\
\hline Teughels et al., 2002 & $\begin{array}{l}\text { Reinforced concrete } \\
\text { beam }\end{array}$ & Young module & $\begin{array}{l}\text { Global damage } \\
\text { function }\end{array}$ & $\begin{array}{l}\text { High correlation } \\
\text { between the } \\
\text { empirical and } \\
\text { analytical data }\end{array}$ \\
\hline \multirow{4}{*}{ Jaishi \& Ren, 2005} & \multirow{4}{*}{$\begin{array}{l}\text { Simple supported } \\
\text { bridge }\end{array}$} & \multirow{4}{*}{$\begin{array}{l}\text { Young module and } \\
\text { moment of inertia }\end{array}$} & Frequency residuals & \multirow{4}{*}{$\begin{array}{l}\text { MAC and modal } \\
\text { flexibility residuals } \\
\text { result in the best } \\
\text { methods to fault } \\
\text { detection }\end{array}$} \\
\hline & & & $\begin{array}{l}\text { MAC related } \\
\text { function }\end{array}$ & \\
\hline & & & $\begin{array}{l}\text { Modal flexibility } \\
\text { residual }\end{array}$ & \\
\hline & & & $\begin{array}{l}\text { Combination of the } \\
\text { above three options }\end{array}$ & \\
\hline He et al., 2008 & $\begin{array}{l}\text { Three-span- } \\
\text { continuous steel truss }\end{array}$ & $\begin{array}{l}\text { Elastic modulus of } \\
\text { steel, equivalent node } \\
\text { mass of deck and } \\
\text { equivalent node mass } \\
\text { of steel sleeper }\end{array}$ & $\begin{array}{l}\text { To minimize the error } \\
\text { function }\end{array}$ & $\begin{array}{l}\text { Good agreement } \\
\text { between the } \\
\text { measured and } \\
\text { theoretical modal } \\
\text { data. }\end{array}$ \\
\hline
\end{tabular}




\begin{tabular}{|c|c|c|c|c|}
\hline Feng et al., 2015 & $\begin{array}{c}\text { Steel short span } \\
\text { bridge }\end{array}$ & $\begin{array}{c}\text { Dynamic } \\
\text { displacement }\end{array}$ & $\begin{array}{c}\text { To minimize the error } \\
\text { function }\end{array}$ & $\begin{array}{c}\text { Good agreement } \\
\text { between the } \\
\text { measured and } \\
\text { simulated } \\
\text { displacements. }\end{array}$ \\
\hline Xia et al., 2014 & Box girder bridge & $\begin{array}{c}\text { Springs stiffness and } \\
\text { elastic modulus of } \\
\text { ballast and girders }\end{array}$ & $\begin{array}{c}\text { To minimize the error } \\
\text { function }\end{array}$ & $\begin{array}{c}\text { Modal parameters } \\
\text { predicted by the FE } \\
\text { agree with the real } \\
\text { ones. }\end{array}$ \\
\hline
\end{tabular}

Table 1. FE model updating papers.

[Sanayei et al., 2015] presented a methodology focused on the simultaneous estimation of bridge stiffness and mass parameters. A scalar objective error function, which has to be minimized, was defined as the difference between analytical and measured displacements, which has been obtained by non-destructive tests conducted in a laboratory bridge model. The results of experiments with static loads and vibrational measurements showed a good match between the updated FE model and measured modal characteristics. Therefore, the authors claimed that if the measured data is quite different from those predicted by the FE model, a fault might have occurred, i.e. the proposed updating strategy could be suitable for a fault detection process. However, it should be noted that the FE model is updated by considering a laboratory model of the bridge, where the impact of the environmental effects on the performance of the bridge cannot be considered, and consequently using this approach false alarms could be activated due to change of the environmental conditions in an in-field application. [Teughels et al., 2002] have developed a two-step FE updating procedure. In the first step, the initial FE model was updated to a reference state, using measured vibrational data of the non-faulty bridge structure and then, in the second step, the reference model was updated in order to reproduce the measured vibrational data of the faulty bridge structure. Therefore, a fault could be identified by comparing the output of the reference (non-faulty) and the faulty FE model. The method was tested on a laboratory model and the results showed that the simulated failure has been correctly identified through an asymmetrical distribution of the updating parameter at the location, where the failure has been introduced. Again, effects of changing environmental conditions were not considered during the analysis and, furthermore, the magnitude of failure and the future evolution of the health state of the bridge were not analysed. [Jaishi \& Ren, 2005] proposed a sensitivity-based updating strategy using four different objective functions: $i$ ) frequency residuals, i.e. the residuals between the natural frequencies provided by the FE model and those measured; ii) a Modal Assurance Criterion (MAC) related function; iii) modal flexibility residual; iv) combination of the first three options.

The MAC related function has been defined as follows:

$$
f(i)=\frac{\left(1-\sqrt{M A C_{i}}\right)^{2}}{M A C_{i}}
$$

where $f(i)$ is the MAC related function at step $i$; the MAC has been computed using the analytical (FE-based result) and the experimental mode shape. 
The modal flexibility is defined by all available mode shape and corresponding natural frequencies:

$$
[F]_{N \times N}=[\Phi]_{N \times M}\left[\frac{1}{\omega^{2}}\right][\Phi]_{N \times M}^{T}
$$

where $[F]$ is the modal flexibility matrix, $[\Phi]$ is the mode shape matrix, $\omega$ is the circular frequency, $M$ is the number of the mode shape considered, and $N$ is the measurement degree of freedom. The method, which has been tested on a laboratory model, showed that in each case of the four objective functions, an accurate fault detection becomes more difficult, as the number of updating parameters increases and, furthermore, the objective function based on the combination of frequency residuals, MAC and modal flexibility residuals, improves the performance of fault detection. Therefore, it is worth mentioning that the choice of the number and type of updating parameters is one of the most challenging aspects of the FE model updating. Indeed, both physical (such as boundary and material properties) and numerical (such as mathematical modelling and numerical solution) uncertainties need to be addressed and reduced by choosing optimal updating parameters that allow a fast and reliable updating of the FE model [Başaĝa et al., 2011]. [He et al., 2008] have analysed a three-span-continuous steel truss bridge, which is monitored by using approximately 150 sensors, including accelerometers, strain gauges, displacement transducers, temperature sensors, weigh-in motion sensors, anemometer and seismograph, and an FE model was developed in ANSYS. A simple method of model updating was proposed by optimizing an objective function based on the difference between analytical and measured frequency, and using the elastic modulus of steel, the equivalent node mass of deck and the equivalent node mass of steel sleeper as updating parameters. Results showed that the maximum error of frequency is $4.09 \%$ and the minimum value of MAC is $85.92 \%$, and thus there is a good agreement between the data provided by the FE model and those retrieved by the sensors. Hence, the method proposed by the authors can be adopted to monitor the evolution of the bridge health state over time. Indeed, data of a real railway bridge was used to update the FE model. However, the method was not verified under changing environmental condition and degrading materials of the bridge. [Feng et al., 2015] proposed an updating strategy of an FE model of a single-span railway bridge by optimizing an objective function, which was based on the difference between simulated and measured dynamic displacements of the bridge. The results showed that the displacements of the real bridge and those predicted using the updated FE model were in good agreement. It is worth noting, however, that while performing fault detection the displacements have shown significant changes only when the health state of the bridge was heavily degraded, therefore, other vibration parameters of the bridge (such as acceleration, natural frequencies, etc.), which can be more sensitive to changes of the health state of the bridge, should be observed. In the same way, [Xia et al., 2014] proposed an FE updating strategy based on the optimization of an objective function that aimed to minimize the differences between the real and simulated modal properties of a real six-span railway bridge. Results showed a good match between the predicted and measured modal parameters of the railway bridge. Although the FE updating strategies based on the optimization of an objective function have shown promising results, FE 
updating strategies based on multi-objective optimisation, which rely on Genetic Algorithm (GA) in order to find the Pareto optimal front [Deb et al., 2002; Di Maio et al., 2015], have demonstrated to outperform single-objective updating strategies [Jin et al., 2014].

\subsubsection{FE updating strategies coupled with machine learning methods}

In order to have a robust fault detection method, FE updating strategies and machine learning methods (such as NN and Genetic Algorithm (GA)) can be coupled. Indeed, these methods are more robust to the presence of noise in experimental data than the direct FE model updating, and they can deal with different sources of data, such as structural parameters and environmental conditions. In what follows, examples of coupling FE model updating strategies with optimization methods in order to optimize the updating procedure and perform a fault detection analysis are presented. Table 2 summarizes the most important information of the presented works.

\begin{tabular}{|c|c|c|c|c|}
\hline Reference & Type of bridge & $\begin{array}{c}\text { Updating } \\
\text { parameter(s) }\end{array}$ & Updating strategy & Results \\
\hline Zhong et al., 2014 & I-steel beam & Not explained & $\begin{array}{c}\text { Third-order } \\
\text { response surface method }\end{array}$ & $\begin{array}{c}\text { The outcomes of the } \\
\text { update FE model are } \\
\text { used as input of a } \\
\text { wavelet neural network } \\
\text { method to perform a } \\
\text { fault detection analysis }\end{array}$ \\
\hline Lee et al., 2002 & Simple span bridge & Stiffness parameters & $\begin{array}{c}\text { Inverse modal } \\
\text { perturbation technique }\end{array}$ & $\begin{array}{c}\text { The outcomes of the } \\
\text { update FE model are } \\
\text { used as input of an ANN } \\
\text { method to perform a } \\
\text { fault detection analysis }\end{array}$ \\
\hline Shabbir et al., 2016 & Cable-stayed bridge & $\begin{array}{c}\text { Group of six parameters } \\
\text { considering stiffness } \\
\text { and tension of different } \\
\text { bridge element }\end{array}$ & $\begin{array}{c}\text { To minimize the error } \\
\text { function }\end{array}$ & $\begin{array}{c}\text { The performance of the } \\
\text { FE model is } \\
\text { considerably improved } \\
\text { by adjusting the set of } \\
\text { updating parameters } \\
\text { considered. }\end{array}$ \\
\hline Chang et al., 2000 & Laboratory model of \\
suspension bridge & $\begin{array}{c}\text { material and } \\
\text { geometrical properties } \\
\text { of the bridge }\end{array}$ & $\begin{array}{c}\text { To minimize the error of } \\
\text { the modal parameters }\end{array}$ & $\begin{array}{c}\text { Structural parameters of } \\
\text { the laboratory model are } \\
\text { correctly identified. }\end{array}$ \\
\hline Moliner et al., 2014 & Box girder bridge & $\begin{array}{c}\text { Mechanical properties } \\
\text { of the bridge }\end{array}$ & $\begin{array}{c}\text { To minimize an error } \\
\text { function based on } \\
\text { natural frequencies and } \\
\text { mode shapes }\end{array}$ & $\begin{array}{c}\text { The updated FE model } \\
\text { shows good prediction } \\
\text { performance. }\end{array}$ \\
\hline
\end{tabular}

Table 2. FE model updating and optimization methods.

[Zhong et al., 2014] have developed a fault detection method that uses the results of the updated FE model as input to a wavelet neural network. The wavelet neural network has a structure similar to ANN, but neurons, which usually characterize the ANN layers, are replaced by wavelet functions. A Morlet wavelet function, which is proportional to the cosine function and Gaussian probability density function, has been selected:

$$
\psi(\bar{x})=\cos (5 \bar{x}) e^{\frac{-\bar{x}^{2}}{2}}
$$


where $\bar{x}$ is the input value of the wavelet neural network, and $\psi$ is the excitation function of the wavelet function. Results showed that the developed method was able to reproduce and predict the displacements of an I-steel beam and a six span continuous bridge and, thus, if abnormal bridge behaviour is recorded, it should be detected by the proposed method. On one hand, the proposed method is a comprehensive method for SHM, as it is able to detect failure of the bridge, and predict the future behaviour of the bridge, i.e. it meets all the four requirements of the fault detection process. On the other hand, environmental conditions are not considered in the analysis and failure scenarios are not analysed. [Lee et al., 2002] have developed an SHM method, merging an updated FE bridge model and an ANN algorithm. A simple-span bridge has been developed both through the FE analysis and laboratory tests, and 8 different failure scenarios have been considered. The FE model has been initially developed, assuming the values of the bending rigidity of the girder section and, then, it was updated using two stiffness parameters, based on the modal parameters obtained from the laboratory tests. The ANN algorithm has been trained using resonant frequencies between before and after faults, and the mode shapes. Results showed that all of the 8 failure scenarios have been successfully detected. However, in general the fault severity has been overestimated, and, also the effect of the air temperature and the future health condition of the bridge were not considered in the analysis. [Shabbir et al., 2016] developed a GA-based FE updating strategy by adopting a sequential niche technique. In this technique, the GA optimisation algorithm was forced to converge to a new and unknown minimum (called niche), once the minimum of the fitness function (i.e. the function that has to be minimized) has been found. In this work, the GA objective function was defined based on the difference between modal parameters (natural frequency and mode shape) provided by the FE model and sensors of a cable-stayed bridge. After the updating, which was carried out recurring of frequency measurement, the frequency errors were less than $3 \%$. The proposed method can be used as a fault detection method due to the possibility of comparing the actual behaviour of the bridge with the predicted behaviour using the FE model. However, the magnitude of the failure, its location and the future behaviour of the bridge were not evaluated. [Chang et al., 2000] presented an FE model updating based on an adaptive NN, which is trained using modal parameters as inputs and structural parameters as outputs, both retrieved from the FE model. A laboratory model of a suspension bridge was considered as the case study. The output of the NN (i.e. the predicted structural parameters) was used as the input of the FE model, which is consequently updated at every step of the iterations, in order to compute the modal parameters of the bridge. The authors considered natural frequencies and mode shapes as input modal parameters of the NN, whereas, the output structural parameters, which were the updating parameters of the FE model, were the material and geometrical properties of the bridge, and the boundary conditions of a deck at tower and pier supports. Results showed this updating process can evaluate the structural parameters of the laboratory model with good accuracy. Hence, when a change in the values of structural parameters occurs, it can be identified by the proposed method, however, false alarms can occur when the method is used for an in-field case study, as the method was optimized by neglecting environmental conditions, and their effects can be misinterpreted by the NN method. [Moliner et al., 2014] presented an updating strategy based on a GA algorithm. An FE model of a 250 
meter long box girder railway bridge was developed, and an objective function, which needed to be minimized, was defined by considering the difference between the measured and expected natural frequencies, and the MAC value. A GA process was carried out in order to update the parameters of the FE model, such as the density and modulus of elasticity of the material of the bridge.The updated FE model showed good results in predicting the behaviour of the bridge in terms of acceleration. Therefore, the proposed method can be used as a fault detection method, i.e. when the behaviour of the real bridge is different from the expected behaviour, which is predicted by the FE model, a fault can be identified.

\subsubsection{Discussion on Finite element model updating strategies}

FE model updating strategies are one of the most common techniques adopted, for assessing the health state of the bridge due to the fact that the behaviour of the bridge can be simulated by considering different expected degradation mechanisms. Furthermore, as soon as new information regarding the health state of the bridge, such as visual inspection reports of the bridge or new measurement of the bridge behaviour, is available the FE model can be updated, and consequently the expected behaviour of the bridge can be compared with the actual behaviour of the real structure. However, the development of an FE model can be complex, time-consuming and expensive. Furthermore, the choice of the updating parameters is a challenge, due to the ill-conditioned problem that requires having a small number of updating parameters. For example, it has been shown that the higher the complexity of the structure, the larger the number of updating parameters: [Lee et al., 2002; Teughels et al., 2002; Jaishi \& Ren, 2005] have studied a simple supported span bridge and beams, and consequently, only one or two updating parameter(s) have been selected; [He et al., 2008; Jin et al., 2014; Sanayei et al., 2015; Shabbir et al., 2016] have studied a more complex bridge structure, from a threespan continuous bridge to a cable-stayed bridge, and the number of updating parameter was consequently increased. However, the increase of the number of the updating parameters can lead to a reduction of the performance of the fault detection method [Jaishi \& Ren, 2005]. It is worth noting that, even if FE models may not represent the real structural behaviour well due to modelling uncertainties, the responses provided by the FE model before the updating procedure need to be relatively similar to those provided by the real measured responses, in order to avoid a divergent updating process. Coupling the FE updating process with an optimization algorithm, such as ANN or GA, can lead to a fast updating of the FE model, however, the performance of the ANN strongly depends on the batch of data that are used during the training phase of the ANN, and the GA algorithm can lead to a local minimum of the fitness function, and consequently the optimal solution can be missed. The size and complexity of the FE modelling and updating strategy can be a challenge for monitoring the bridge health condition in real-time. For this reason, a simple supported beam is analysed by the majority of the authors. The time-consuming FE model updating process, which often requires that the FE model parameters are selected using expert knowledge, can jeopardize a goal of achieving a continuous SHM, and the noise in the data of the measured bridge behaviour can give misleading results of the FE model updating. Finally, the magnitude of the failure, the future behaviour of the bridge and the effect of environmental condition on the modal parameters of the bridge generally are not considered in the FE analysis. Consequently, only 
the first two requirements of the fault detection process (identification of the failure existence and failure location) are satisfied.

\subsection{Non-model-based fault detection methods}

In the last decades, in order to identify the presence of failure in a bridge, various fault detection methods have been developed by relying only on the analysis of the bridge behaviour without developing a model of the structure. Indeed, non-model-based methods can perform a fast analysis without requiring the computational effort of the FE model updating methods, and consequently, rapid information about the health state of the bridge could be provided to bridge managers. In literature, non-model-based methods have demonstrated to be suitable for realtime monitoring of complex systems, such as nuclear systems [Zio et al., 2010], industrial processes (including chemicals, microelectronics manufacturing, iron and steel, pharmaceutical processes, and power distribution networks) [Qin, 2012; Yin et al., 2014], petroleum and natural gas systems [Galotto et al., 2015] and electric vehicles [Rigamonti et al., 2016]. For these reasons, in what follows a survey of non-model-based methods for bridge SHM is provided. Particularly, the ANN method has been intensively used as the fault detection method in a structural engineering framework, and consequently, a section 3.2.1 presents the analysis of the ANN-based fault detection methods. A slightly different neural network structure, which is commonly used in the bridge SHM, is the Probabilistic Neural Network (PNN) that is also presented [Specht, 1990]. Section 3.2.2 discuss other non-model-based methods presented in literature that are based on statistical and unsupervised clustering methods, and, finally, section 3.2.3 shows some works based on BBNs, which can evaluate the health state of individual elements on the bridge as well as considering the structure as a whole [Andersen et al., 2006].

\subsubsection{Neural Network for Railway Bridge fault assessment}

The Artificial Neural Networks (ANNs) algorithm tries to replicate the behaviour of the brain cells. A biological system is able to learn behaviours, to solve complex problems and to handle nonlinear, imprecise and fuzzy information and, therefore, a lot research effort has been made to develop an artificial method to reproduce such incredible biological characteristics [Basheer \& Hajmeer, 2000]. Fast processing and high fault-tolerance and capability of learning, which allows the system to adapt to changing behaviour of the system under analysis are two of the main characteristics of ANN. It is worth underlining that the ANN learning capacity, which is performed by iteratively presenting many different training patterns to the ANN (like humans learn from experience), aims to find out a link between causes (inputs) and consequences (outputs) of the system behaviour, and consequently, the results of the ANN strongly rely on the nature, quality and reliability of the training data, which need to be well-known pairs of input disturbances and corresponding outputs behaviour of the bridge. The training process can follow two different strategies, feed-forward and back-propagation, which can be either supervised or un-supervised [Demuth et al., 2014]. 
According to the analogy between the ANN and the biological brain system, the ANN is composed of neurons, also called nodes, which are simple computational units, directly linked by weighted connections. Fig. 2 shows a simple ANN structure, where each circle represents a neuron. Those on the left side are the input neurons describing the input variables of the system. The hidden layer neurons, the middle nodes in Fig. 2, process the information provided by the input nodes and pass them to the output nodes (the right side of Fig. 2). The input neurons are connected with the hidden layer neurons through weight parameters, which are represented by links with arrows in Fig. 2. The same description can be used for the connection between the hidden layer neurons and the output neurons. There are no general rules for the choice of the number of neurons; the number of the input neurons is generally taken to be equal to the number of system variables, which seem to significantly affect the output due the information that each input node provides to the hidden layer nodes; the number of hidden nodes, however, is kept to as low as possible through a trial and error procedure, in order to reach the best solution in terms of computational time cost and residual error. This procedure is one of the most important aspects of ANN usage. The number of output neurons is determined by the number of quantities that need to be estimated in the problem. The theoretical basis of the ANN are described in [Bishop, 1995]. In the area of bridge SHM, a slightly different neural network, called Probabilistic Neural Network (PNN) [Specht, 1990], is commonly used. The basic concept of $\mathrm{PNN}$ is presented in section 3.2.1.1.

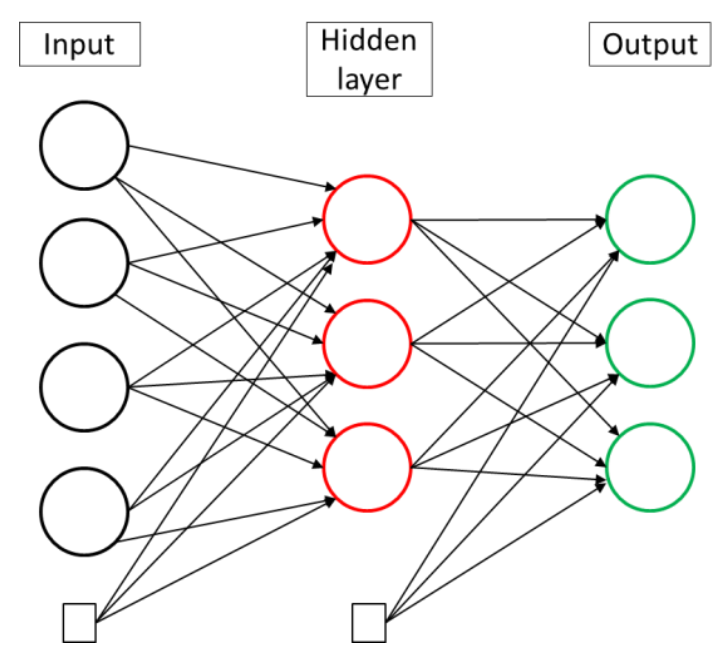

Fig. 2. Schematics of the ANN.

\subsubsection{Probabilistic neural networks}

The PNN structure is similar to the ANN using the back-propagation algorithm, but it differs in terms of the activation functions, that are not sigmoidal. The PNN is based on the Bayes decision rule and the estimations of probability density functions. Assume that the health state of the bridge can be denoted by, $\vartheta$, and it may belong to two different categories, $\vartheta_{a}$ for healthy states, and $\vartheta_{b}$ for faulty states. Given a set of measurements, $X=\left\{x_{1}, x_{2}, \ldots, x_{p}\right\}$, the 
decision on the category of the health state of the bridge, $d(X)$, based on the Bayes decision rule, is performed as:

$$
\left\{\begin{array}{lll}
\text { if } & h_{a} l_{a} f_{a}>h_{b} l_{b} f_{b} \Rightarrow & d(X) \in \vartheta_{a} \\
\text { if } & h_{a} l_{a} f_{a}<h_{b} l_{b} f_{b} \Rightarrow & d(X) \in \vartheta_{b}
\end{array}\right.
$$

where $f_{a}$ and $f_{b}$ are the probability density functions for the healthy and faulty bridge states, respectively; $h_{a}$ and $h_{b}$ are the a priori probability of occurrence of the healthy and faulty bridge states, respectively; $l_{a}$ and $l_{b}$ are the losses that the system has, when the category of the health state of the bridge is misclassified, i.e., $d(X) \in \vartheta_{b}$, when actually $\vartheta=\vartheta_{a}$ or $d(X) \in \vartheta_{a}$, when actually $\vartheta=\vartheta_{b}$. The loss functions require subjective evaluation [Specht, 1990]. The accuracy of the Bayes decision rule depends on the ability to estimate the probability density functions, based on training patterns.

Fig. 3 shows the architecture of the PNN. The input layer is fed with a set of measurements, $X=\left\{x_{1}, x_{2}, \ldots, x_{p}\right\}$, to be classified; in the hidden layer, each neuron is the product of the set of measurements, $X=\left\{x_{1}, x_{2}, \ldots, x_{p}\right\}$, and the weights vector, $w, z=X \cdot w$, and, as a substitute of the sigmoidal activation function, commonly used in the ANN, the activation functions used in the PNN are as follows:

$$
g\left(z_{i}\right)=e^{\left(\frac{z_{i}-1}{\sigma_{p n}^{2}}\right)}
$$

where $\sigma_{p n}^{2}$ is the smoothing parameter, which has to be iteratively estimated on the basis of the classification performance of the PNN [Kusy \& Zajdel, 2014].

Then each neuron of the summation layer receives all the outputs of the hidden layer neurons that are associated with a given class. For example, in Fig. 3, the summation neuron on the left receives the output of the hidden layer neurons belonging to the dashed box, which are the neurons associated with the healthy class, $\vartheta_{a}$. The output of the healthy summation neuron is expressed as:

$$
f_{a}(X)=\sum_{i=1}^{p} z_{i}=\sum_{i=1}^{p} e^{\left(\frac{X \cdot w_{i}-1}{\sigma_{p n}}\right)}
$$

For the faulty state, $\vartheta_{b}$, the mathematical description is equivalent to the one in Eq. (15), referring to the dotted box in the hidden layer in Fig. 3. 


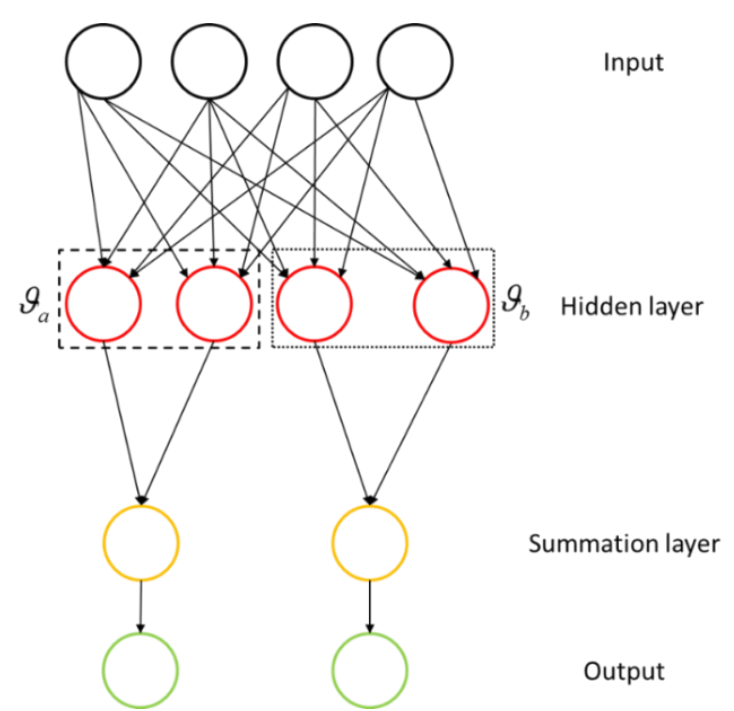

Fig. 3 Schematic of the PNN.

\subsubsection{Application of the ANN and PNN for Structural Health monitoring}

The Neural Network fault detection methods (ANN and PNN) have generally demonstrated to be effective in revealing bridge failures, unless the noise of the input data is high. These methods are one of the most used fault detection method in the structural framework. The following analysis is divided in three sections, based on the nature of the ANN architecture: $a$ ) Back-Propagation Neural Network (BPNN); $b$ ) feed-forward neural network; $c$ ) PPN. It is worth noting that the difference between the back-propagation and the feed-forward architecture depends only on the strategy adopted during the training of the network: in the backpropagation the errors of the hidden (output) layers are back-propagate to the earlier layers in order to find the minimum of the error function; on the other hand, the feed-forward neural network is trained by adjusting the weights and biases of the hidden layers in order to find the minimum of the error function [Demuth et al., 2014].

\section{a) Back-Propagation Neural Network}

In this section BPNN-based methods, which have been applied to SHM of bridges, are described by highlighting the type of bridge analysed, and the architecture of the BPNN. The BPNN main property relies on the computation of the errors function, where the errors are back-propagated from the output neurons towards the hidden neurons. Finally, the results of each work are presented. Table 3 shows the main characteristics of the discussed works. It is worth noting that the majority of the presented works is based on results of a FE model. 


\begin{tabular}{|c|c|c|c|c|c|c|c|}
\hline Reference & $\begin{array}{l}\text { Type of } \\
\text { bridge }\end{array}$ & $\begin{array}{l}\text { Type of } \\
\text { NN }\end{array}$ & $\begin{array}{l}\text { Number of } \\
\text { input nodes }\end{array}$ & $\begin{array}{c}\text { Number of } \\
\text { hidden nodes }\end{array}$ & $\begin{array}{c}\text { Number of } \\
\text { output nodes }\end{array}$ & $\begin{array}{c}\text { Type of input } \\
\text { data }\end{array}$ & Results \\
\hline \multirow{2}{*}{$\begin{array}{c}\text { Shu et al., } \\
2013\end{array}$} & \multirow{2}{*}{$\begin{array}{c}\text { FE model of } \\
\text { Banafjäl } \\
\text { bridge, } \\
\text { Sweden }\end{array}$} & \multirow{2}{*}{$\begin{array}{l}\text { BPNN } \\
\text { single } \\
\text { layer }\end{array}$} & \multirow[b]{2}{*}{ Not explained } & $\begin{array}{c}19 \text { for fault } \\
\text { detection }\end{array}$ & \multirow[b]{2}{*}{ Not explained } & \multirow[b]{2}{*}{$\begin{array}{l}\text { Displacements } \\
\text { and acceleration }\end{array}$} & \multirow{2}{*}{$\begin{array}{l}\text { Results strongly } \\
\text { depend on the } \\
\text { position of the } \\
\text { fault and on the } \\
\text { load and velocity } \\
\text { of the train }\end{array}$} \\
\hline & & & & $\begin{array}{c}23 \text { for fault } \\
\text { diagnostic }\end{array}$ & & & \\
\hline \multirow{8}{*}{$\begin{array}{l}\text { Lee et al., } \\
2005\end{array}$} & \multirow{2}{*}{$\begin{array}{l}\text { FE model of } \\
\text { a beam }\end{array}$} & \multirow{8}{*}{$\begin{array}{l}\text { BPNN } \\
\text { multi } \\
\text { layers }\end{array}$} & \multirow[b]{2}{*}{20} & 20 first layer & \multirow[b]{2}{*}{8} & \multirow{8}{*}{$\begin{array}{l}\text { Mode shape, } \\
\text { mode shape } \\
\text { difference before } \\
\text { and after failure } \\
\text { and mode shape } \\
\text { ratio for the first } \\
\text { four modes }\end{array}$} & \multirow{8}{*}{$\begin{array}{l}\text { Generally, the } \\
\text { method shows } \\
\text { good accuracy } \\
\text { with some false } \\
\text { alarms in the } \\
\text { laboratory and } \\
\text { Hannam bridge } \\
\text { case study }\end{array}$} \\
\hline & & & & $\begin{array}{c}20 \text { second } \\
\text { layer }\end{array}$ & & & \\
\hline & \multirow{2}{*}{$\begin{array}{c}\text { FE model of } \\
\text { single span } \\
\text { bridge }\end{array}$} & & \multirow[b]{2}{*}{98} & 60 first layer & \multirow[b]{2}{*}{40} & & \\
\hline & & & & $\begin{array}{c}40 \text { second } \\
\text { layer }\end{array}$ & & & \\
\hline & \multirow{2}{*}{$\begin{array}{c}\text { Laboratory } \\
\text { model of } \\
\text { bridge }\end{array}$} & & \multirow[b]{2}{*}{24} & 24 first layer & \multirow[b]{2}{*}{8} & & \\
\hline & & & & $\begin{array}{c}8 \text { second } \\
\text { layer }\end{array}$ & & & \\
\hline & $\begin{array}{c}\text { Hannam } \\
\text { Grand }\end{array}$ & & \multirow{2}{*}{80} & 60 first layer & \multirow{2}{*}{40} & & \\
\hline & $\begin{array}{c}\text { bridge, South } \\
\text { Korea }\end{array}$ & & & $\begin{array}{c}60 \text { second } \\
\text { layer }\end{array}$ & & & \\
\hline \multirow{2}{*}{$\begin{array}{c}\text { Al- } \\
\text { Rahmani et } \\
\text { al., } 2012\end{array}$} & \multirow[t]{2}{*}{$\begin{array}{c}\text { FE model of } \\
\text { a beam }\end{array}$} & \multirow[t]{2}{*}{ BPNN } & 6 & 19 & 3 & \multirow{2}{*}{$\begin{array}{l}\text { Materials } \\
\text { characteristics of } \\
\text { the beam and } \\
\text { crack parameters }\end{array}$} & \multirow{2}{*}{$\begin{array}{l}\text { Although the } \\
\text { error of the } \\
\text { methods is high, } \\
\text { its accuracy } \\
\text { improves as the } \\
\text { number of } \\
\text { stiffness nodes } \\
\text { increases. }\end{array}$} \\
\hline & & & 6 & 19 & 5 & & \\
\hline $\begin{array}{l}\text { Lee et al., } \\
2007\end{array}$ & $\begin{array}{c}\text { FE and } \\
\text { laboratory } \\
\text { model of } \\
\text { simply } \\
\text { supported } \\
\text { three steel } \\
\text { girders }\end{array}$ & $\begin{array}{l}\text { Multi- } \\
\text { layer } \\
\text { BPNN }\end{array}$ & 15 & 10 & 9 & $\begin{array}{l}\text { Acceleration or } \\
\text { strain }\end{array}$ & $\begin{array}{l}\text { Strain-based } \\
\text { ANN performs } \\
\text { better than the } \\
\text { acceleration- } \\
\text { based ANN. }\end{array}$ \\
\hline $\begin{array}{l}\text { Hakim et } \\
\text { al., } 2013\end{array}$ & $\begin{array}{l}\text { FE model of } \\
\text { a steel girder } \\
\text { bridge }\end{array}$ & BPNN & 5 & 14 & 1 & $\begin{array}{l}\text { Natural } \\
\text { frequencies }\end{array}$ & $\begin{array}{l}\text { Good accuracy in } \\
\text { predicting the } \\
\text { severity of } \\
\text { simulated } \\
\text { damages. }\end{array}$ \\
\hline \multirow{2}{*}{$\begin{array}{l}\text { Park et al., } \\
2009\end{array}$} & \multirow{2}{*}{$\begin{array}{c}\mathrm{FE} \text { and } \\
\text { laboratory } \\
\text { model of } \\
\text { simply } \\
\text { supported } \\
\text { beam }\end{array}$} & \multirow{2}{*}{ BPNN } & 50 & 50 & $\begin{array}{l}\text { Depending on } \\
\text { the case study }\end{array}$ & Acceleration & \multirow{2}{*}{$\begin{array}{l}\text { Good accuracy as } \\
\text { sequential FD } \\
\text { method: } \\
\text { acceleration- } \\
\text { based NN } \\
\text { monitors the } \\
\text { bridge in real } \\
\text { time, modal- } \\
\text { based NN } \\
\text { assesses the } \\
\text { location and } \\
\text { severity of the } \\
\text { failure. }\end{array}$} \\
\hline & & & $\begin{array}{l}\text { Depending on } \\
\text { the case study }\end{array}$ & $\begin{array}{l}\text { Depending on } \\
\text { the case study }\end{array}$ & $\begin{array}{l}\text { Depending on } \\
\text { the case study }\end{array}$ & Modal data & \\
\hline
\end{tabular}

Table 3. Examples of fault detection methods based on the BPNN described in this section.

[Shu et al., 2013] have developed a BPNN fault detection method, based on statistical properties of the responses of a single-span and single-track concrete railway bridge. Authors have demonstrated that the performance of the BPNN decreases, as the signal noise increases and the load of the train that was passing over the bridge decreases. Furthermore, the fault 
location has been demonstrated to be an issue; indeed, a fault that has occurred in the middle of the bridge was easier to detect than at the end of the bridge. It should be noted that one of the biggest issue of machine learning methods for fault detection is the selection of the training data set. Indeed, changing environmental conditions, such as air temperature, wind and traffic, strongly affect the response of the bridge, and, consequently, the training set should contain these different behaviours of the bridge, in order to correctly assess and predict the health state of the bridge. [Lee et al., 2005] have presented an ANN-based fault detection method by studying four different bridge case studies (FE model of a beam, FE model of single span bridge, laboratory model of bridge and Hannam Grand bridge, South Korea) with three different ANN input strategies: $i$ ) mode shapes; ii) mode shape differences between before and after failure; iii) mode shape ratios for the first four modes. Results showed that for all case studies, even when some false alarms have been raised, the proposed method was able to identify the faults, using the differences or the ratios of the mode shape between before and after the failure, as the data input. Particularly as the environmental conditions were not considered in the analysis, false alarms were raised during the analysis of the real bridge. [AlRahmani et al., 2012] have analysed two ANN methods to predict the location and the growth of cracks in an FE model of a simply supported beam. Results showed that both ANNs, which differ in terms of structures and input data, could predict the growth of the cracks in the beam. However, the ANN prediction error was quite high due to the fact that the parameters that describe the crack characteristic were not considered in the training set of data. [Lee et al., 2007] developed a BPNN to identify failure of a simply supported steel bridge. Two ANNs have been considered by modifying the nature of the input data: $i$ ) acceleration-based data; $i i$ ) strain-based data. Results showed that the strain-based ANN performed better than the acceleration-based ANN, i.e. the misclassification rate for the strain-based ANN was lower than that obtained with the acceleration-based ANN (for example, for the lowest fault severity the acceleration-based ANN have a misclassification rate equal to $35.80 \%$ instead of the strainbased ANN of $8.75 \%$ ). Although the method, which was tested on a laboratory model of a bridge, showed good performance in the localization of the failure by using the strain as the input to the ANN, only the first two levels of the four requirements of the fault detection process was accomplished, i.e. the magnitude of the failure and the future behaviour of the bridge were not assessed. [Hakim et al., 2013] developed a BPNN in order to identify failure and to assess severity of a steel girder bridge. Results showed that the trained ANN was able to identify with high accuracy (higher than 90\%) the failure severity of the test patterns. However, the ANN method was trained and tested on an FE model of a steel bridge, and consequently, all the external influences on the bridge behaviour were not considered. Finally, [Park et al., 2009] proposed a sequential fault detection method based on an acceleration-based ANN (ABNN), which was used to monitor the behaviour of the bridge and to detect the occurrence of a failure by using acceleration data as input, and on a modal feature-based ANN (MBNN), which was used to estimate the location and the severity of the occurred failure by using mode shape and modal strain energy as input. A simply supported aluminium beam was selected as the case study. Results showed that the occurrence, the location and severity of failure is correctly identified by firstly adopting the ABNN and, sequentially, the MBNN. It is worth noting that modal strain energies were used as the input to the MBNN, and consequently the impact of 
environmental changes (air temperature, wind, etc.) on this fault detection method can be lower than using the methods, trained with acceleration data [Lee et al., 2005].

\section{b) Feed-forward Neural Network}

In this section Feed-forward ANN methods applied to bridges SHM are presented, by analysing their performance in terms of type of bridge studied, architecture of the ANN and results of the fault detection process. Table 1 shows the main characteristics of the discussed works.

\begin{tabular}{|c|c|c|c|c|c|c|c|}
\hline Reference & Type of bridge & Type of NN & $\begin{array}{l}\text { Number of } \\
\text { input nodes }\end{array}$ & $\begin{array}{c}\text { Number of } \\
\text { hidden } \\
\text { nodes }\end{array}$ & $\begin{array}{c}\text { Number } \\
\text { of } \\
\text { output } \\
\text { nodes }\end{array}$ & $\begin{array}{c}\text { Type of input } \\
\text { data }\end{array}$ & Results \\
\hline \multirow[b]{2}{*}{$\begin{array}{l}\text { Mehrjoo et } \\
\text { al., } 2008\end{array}$} & $\begin{array}{c}\text { FE model of a } \\
\text { simple truss }\end{array}$ & \multirow[b]{2}{*}{$\begin{array}{c}\text { feed-forward } \\
\text { NN }\end{array}$} & 32 & 50 & 5 & \multirow[b]{2}{*}{$\begin{array}{l}\text { Natural } \\
\text { frequencies and } \\
\text { mode shape }\end{array}$} & $\begin{array}{c}98 \% \text { of correct } \\
\text { classification }\end{array}$ \\
\hline & $\begin{array}{l}\text { FE model of } \\
\text { Louisville } \\
\text { bridge, UK }\end{array}$ & & $\begin{array}{l}\text { Varying the } \\
\text { number of the } \\
\text { inputs }\end{array}$ & $\begin{array}{l}\text { Depending } \\
\text { on the } \\
\text { number of } \\
\text { the inputs }\end{array}$ & 6 & & $\begin{array}{c}\text { From } 90 \text { to } 98 \% \\
\text { of correct } \\
\text { classification }\end{array}$ \\
\hline \multirow{2}{*}{$\begin{array}{l}\text { Yeung et al., } \\
2005\end{array}$} & \multirow{2}{*}{$\begin{array}{l}\text { FE model of } \\
\text { Clifton } \\
\text { suspension } \\
\text { bridge, UK }\end{array}$} & PRAN & 1 & \multirow{2}{*}{$\begin{array}{l}\text { No hidden } \\
\text { nodes }\end{array}$} & $\begin{array}{c}\text { From } 23 \\
\text { to } 99\end{array}$ & \multirow{2}{*}{$\begin{array}{c}\text { Feature vector } \\
\text { based on } \\
\text { vibration } \\
\text { signature }\end{array}$} & $\begin{array}{l}\text { From } 0 \% \text { to } \\
100 \% \text { of correct } \\
\text { classification }\end{array}$ \\
\hline & & DIGNET & 1 & & $\begin{array}{l}\text { From } 4 \\
\text { to } 90\end{array}$ & & $\begin{array}{c}\text { From } 0 \% \text { to } \\
100 \% \text { of correct } \\
\text { classification }\end{array}$ \\
\hline \multirow[b]{2}{*}{ Li et al., 2011} & \multirow{2}{*}{$\begin{array}{c}\text { FE and } \\
\text { laboratory } \\
\text { model of simply } \\
\text { supported beam }\end{array}$} & $\begin{array}{c}\text { Feed-forward } \\
\text { NN }\end{array}$ & 10 & \multirow{2}{*}{$\begin{array}{c}5 \text { hidden } \\
\text { layers with } \\
10,8,6,4 \\
\text { and } 2 \text { nodes, } \\
\text { respectively }\end{array}$} & \multirow[b]{2}{*}{1} & \multirow{2}{*}{$\begin{array}{l}\text { Frequency } \\
\text { response } \\
\text { functions }\end{array}$} & \multirow{2}{*}{$\begin{array}{l}\text { The ensemble- } \\
\text { ANN provides } \\
\text { more accurate } \\
\text { results than the } \\
\text { single ANN }\end{array}$} \\
\hline & & $\begin{array}{c}\text { Ensemble of } \\
\text { ANNs }\end{array}$ & 7 & & & & \\
\hline $\begin{array}{l}\text { Cremona et } \\
\text { al., } 2012\end{array}$ & $\begin{array}{l}\text { Steel railway } \\
\text { bridge }\end{array}$ & $\begin{array}{c}\text { Feed-forward } \\
\text { NN }\end{array}$ & Not explained & $\begin{array}{c}\text { Not } \\
\text { explained }\end{array}$ & $\begin{array}{c}\text { Not } \\
\text { explained }\end{array}$ & $\begin{array}{l}\text { Symbolic data of } \\
\text { acceleration, } \\
\text { natural } \\
\text { frequencies and } \\
\text { mode shapes }\end{array}$ & $\begin{array}{l}\text { The method } \\
\text { provides good } \\
\text { accuracy by } \\
\text { using the } \\
\text { different input } \\
\text { data. }\end{array}$ \\
\hline
\end{tabular}

Table 1. Examples of fault detection methods based on the feed-forward ANN.

[Mehrjoo et al., 2008] have studied the fatigue faults of joints in truss bridges, and by developing a multi-layered feed-forward ANN, an accuracy detection of the FE simulated failures higher than $90 \%$ has been achieved. However, the accuracy of the results and the architecture of the ANN strongly depended on the number of vibration modes, i.e. natural frequencies and mode shapes that have been considered as input of the ANN. [Yeung et al., 2005] have analysed an FE model of an iron suspension bridge, by simulating corrosion of the riveted splices. Two unsupervised ANN algorithms have been tested: $i$ ) Probabilistic Resource Allocating Network (PRAN); ii) DIGNET network. The difference between the two ANN strategies lied in the rules adopted during the training of the network: the former built class clusters using the evaluation of the Gaussian probability density function; the latter built class clusters using spherical attraction regions and the similarity between the presented training pattern and the centre of the cluster. Results of the considered case study showed that the misclassification of the PRAN was less than $5 \%$ with 10 clusters and more than $20 \%$ with 100 
clusters; on the other hand, the DIGNET misclassification was less than 5\% with 10 clusters and is about $13 \%$ with 100 clusters. The number of clusters was consequently another parameter to be optimized and, moreover, the changing traffic over the bridge was considered as the only environmental factor. Only the location of the failure was identified, but not the magnitude. [Li et al., 2011] presented an ensemble of feed-forward NN by using Frequency Response Function (FRF) as measured behaviour of the bridge. A laboratory model and an FE model of a simply supported beam were developed and divided in seven equal section. An ANN, which gave as output the severity and the location of a possible failure, was developed for each section and it was trained using principal component reduced FRF data. An ensembleANN was then developed in order to identify the failure of the beam based on the output of each ANN. The performance of the ensemble-ANN was compared with the result of an ANN that was developed considering the beam as a whole. Results showed that the ensemble-ANN led to more accurate detection of the beam failures. However, the accuracy strongly depended on the level of noise, i.e. as the noise increased, the accuracy of the method decreased. Finally, [Cremona et al., 2012] discussed a NN-based classification method in order to assess the health state of a steel railway bridge over time. Particularly, strengthening works were carried out on the bridge, and the authors aimed to assess the health state of the strengthened bridge. Therefore, symbolic data of the measured acceleration, natural frequencies and mode shapes were used as the input to a feed-forward $\mathrm{NN}$, which has been trained using historical measurements. Results showed that when a new and unknown measurement was available, the proposed method was able to correctly assess the health state of the bridge up to $93 \%$ of the tested scenarios. It should be noted that due to the availability of a vast database of recorded behaviour of a real bridge, good results in terms of assessment of the health state of the bridge were achieved. Finally, it is worth mentioning that the fault detection method proposed by [Cremona et al., 2012], also has been applied successfully to the structural health monitoring of a highway bridge, by adapting the parameters of the SHM method to the behaviour and environmental conditions of the new bridge case study [Alves et al., 2015c].

\section{c) Probabilistic Neural Networks}

In this section PNN-based methods for fault detection of bridges are discussed. The type of bridge analysed is presented, by describing the architecture of the PNN and results of the fault detection process. Table 2 shows the main characteristics of the discussed works. 


\begin{tabular}{|c|c|c|c|c|c|c|c|}
\hline Reference & Type of bridge & Type of NN & $\begin{array}{c}\text { Number of } \\
\text { input nodes }\end{array}$ & $\begin{array}{c}\text { Number of } \\
\text { hidden nodes }\end{array}$ & $\begin{array}{c}\text { Number of } \\
\text { output nodes }\end{array}$ & $\begin{array}{c}\text { Type of } \\
\text { input data }\end{array}$ & Results \\
\hline \multirow{2}{*}{$\begin{array}{l}\text { Zhou et al., } \\
2014\end{array}$} & $\begin{array}{l}\text { FE model of } \\
\text { Tsing Ma } \\
\text { bridge, China }\end{array}$ & \multirow{2}{*}{ PNN } & 20 & 1600 & 16 & \multirow{2}{*}{$\begin{array}{c}\text { Modal } \\
\text { frequencies } \\
\text { change ratio }\end{array}$} & $\begin{array}{l}\text { From } 26 \% \text { to } \\
94 \% \text { of } \\
\text { correct } \\
\text { classification }\end{array}$ \\
\hline & $\begin{array}{l}\text { FE model of } \\
\text { Ting Kau } \\
\text { bridge, China }\end{array}$ & & From 5 to 20 & 2000 & 17 & & $\begin{array}{l}\text { From } 46 \% \text { to } \\
84 \% \text { of } \\
\text { correct } \\
\text { classification }\end{array}$ \\
\hline \multirow{2}{*}{$\begin{array}{l}\text { Lee \& Yun, } \\
2007\end{array}$} & $\begin{array}{c}\text { FE model of a } \\
\text { simple } \\
\text { supported } \\
\text { bridge }\end{array}$ & \multirow{2}{*}{ PNN } & 1 & 40 & 40 & \multirow{2}{*}{ Mode shape } & $\begin{array}{l}\text { PNN shows } \\
\text { good results } \\
\text { for single } \\
\text { failure, }\end{array}$ \\
\hline & $\begin{array}{l}\text { Hannam Grand } \\
\text { bridge, South } \\
\text { Korea }\end{array}$ & & 1 & 28 & 28 & & $\begin{array}{l}\text { whereas it } \\
\text { fails to } \\
\text { detect } \\
\text { multiple } \\
\text { failures }\end{array}$ \\
\hline $\mathrm{Ni}, 2014$ & $\begin{array}{c}\text { Tsing Ma } \\
\text { Bridge }\end{array}$ & PNN & 52 & 1600 & 16 & $\begin{array}{l}\text { Natural } \\
\text { frequency } \\
\text { change } \\
\text { ratios and } \\
\text { translational } \\
\text { components } \\
\text { mode vector }\end{array}$ & $\begin{array}{c}\text { The } \\
\text { The } \\
\text { accuracy of } \\
\text { the } \\
\text { identification } \\
\text { of the failure } \\
\text { location } \\
\text { increases as } \\
\text { the noise } \\
\text { decreases. }\end{array}$ \\
\hline
\end{tabular}

Table 2. Examples of fault detection methods based on the PNN.

[Zhou et al., 2014] developed a PPN method by using change ratios for the vibration modes of the structure before and after the fault, as input data. Two case studies, a double deck suspension bridge and a cable-stayed bridge, have been investigated. In both cases, the PNN results showed that the fault identification accuracy increased as the noise level decreased (for example, the fault identification accuracy dropped from $94.91 \%$ to $26.28 \%$ by increasing the noise) and, furthermore, the fault identification accuracy increased also when more modal frequencies have been included in the PNN input vector (for example, using 20 modal frequencies the accuracy was equal to $84.33 \%$, whereas using only 5 modal frequencies the accuracy was equal to 58.75\%). [Lee \& Yun, 2007] presented a PNN fault detection technique, based on the estimated modal parameters of a simply supported bridge model. The results of damage localization showed that a single faulty member has been successfully identified in all the cases, which means that the PNN correctly identified the classes of the failure. However, with multiple faults the damage localization is failed in all the cases due to misclassification of the damaged classes by the PNN. Finally, [Ni, 2014] studied a suspension bridge by diving its deck in 16 elements and developing a PNN. Natural frequency change ratios, and the three translational components of the first mode vector at different location of the bridge were considered as input of the PNN. Results showed that the accuracy of the identification of the failure location increased as the noise decreased (e.g. it moved from the $99.14 \%$ with a noise of the $0.025 \%$ to the $73.75 \%$ when the noise was $0.1 \%$ ).

Although good performance was demonstrated by each PNN method, only [Ni, 2014] considered the environmental effects on the bridge behaviour in the PNN analysis. Furthermore, the presented PPN methods focused only on the identification of the existence of 
a failure and on its location, but the failure magnitude and the future behaviour of the bridge under degrading conditions were not considered.

\subsubsection{Discussion on Neural Networks methods}

One of the most important issues of the ANN strategy is the selection of the model structure, i.e. the number of neurons. The number of the input neurons is, generally, taken to be equal to the number of system variables of interest (for example, a feature vector based on the Fast Fourier Transform [Duhamel \& Vetterli, 1990] of the bridge response is used as input of the ANN developed by [Yeung et al., 2005]; six physical properties, such as the stiffness ratio and beam length and wide, etc. are used as input of the ANN proposed by [Al-Rahmani et al., 2012]). However, the optimal number of input nodes can be defined also by trial and error procedure, as proposed by [Mehrjoo et al., 2008]. The number of hidden nodes is usually kept to as low as possible, in order to reach the best solution in terms of computational time cost and residual error. This procedure is one of the most critical aspects of the use the ANN, and it is generally addressed by using a trial and error procedure [Lee et al., 2005; Lee et al., 2007; Mehrjoo et al., 2008; Park et al., 2009; Al-Rahmani et al., 2012; Hakim et al., 2013]. In order to point out a methodological criterion to choose the optimal ANN structure, a Bayesian process can be adopted by considering that an increasing number of the hidden layers leads to higher accuracy of data fitting, but poor predictions for new failure cases may be achieved due to an over-parameterization of the problem [Arangio et al., 2014]. Indeed, if the ANN is overparameterized, i.e. the number of hidden nodes is too high, the ANN is optimal to mimic the training set, but it is unable to manage new and unknown patterns. Furthermore, the best ANN structure is chosen for a particular case study and, thus, it has to be changed if the case study changes (i.e. the bridge model under study or the number of the modal properties is changed), as demonstrated by [Lee et al., 2005; Lee et al., 2007; Mehrjoo et al., 2008; Park et al., 2009; Al-Rahmani et al., 2012].

The performance of the ANN in terms of accuracy depends on the data used in the training set. For example, [Lee \& Yun, 2007] have shown that if the PNN is trained only with data containing a single failure, the PNN method is not able to identify multiple failures. Furthermore, [Yeung et al., 2005; Mehrjoo et al., 2008; Zhou et al., 2014] have demonstrated that the ANN fault detection accuracy decreases and, thus, the number of false alarms increases, as the number of the considered modal characteristics (e.g., the number of considered natural frequencies or mode shapes) decreases and the noise of the data increases. Moreover, [Shu et al., 2013] have shown that the accuracy of the ANN is affected by the fault location: a failure close to the end of the bridge is more difficult to be detected than a failure in the middle of the bridge.

Regarding the desiderata of the SHM process, the sensors system is not usually described in the literature. The prediction of future health state and its components is not considered, and the influence of the degradation of individual bridge components on the whole bridge health state is not also accounted for. Changes of the environmental condition are generally not considered, and the analysis of the uncertainties (both epistemic and aleatory) is missing. 
Finally, although the ANN method has been applied in a number of studies, it has two main limitations:

i) the ANNs and PNNs methods are able to approximate any function, but they are not directly correlated to the bridge model, and thus they do not represent the physical structure of the bridge. A model with the properties showed by ANNs and PNNs is a black-box model. Thus, the expertise of the structural engineers that have developed the FE model of the bridges is lost, as the fault detection methods based on the $\mathrm{NN}$ rely only on the data retrieved by the bridge.

ii) there is no standard method to choose the optimal structure of the NN. Furthermore, the method also needs a definition of the best training algorithm, in order to achieve fast convergence of the training phase, and finally, a criterion to rigorously define how much and what type of training data are required, has to be defined [Lee et al., 2014; Kan et al., 2015]

\subsubsection{Other non-model-based methods examples}

Due to the fact that non-model-based methods can assess the health state of the bridge by only analysing the behaviour of the bridge provided by the measurement system, and, thus, the development of a model of the structure (such as an FE model) is not required, a rapid assessment of the health state of the bridge using such techniques can be achieved. Therefore, as it has been pointed out in the introduction of section 3.2, non-model based methods have demonstrated to be suitable for real-time monitoring of complex systems, and consequently, in what follows, a survey of non-model-based methods for bridge SHM is provided. The methods are divided in three sub-sections: $a$ ) fault detection using a machine learning and statistical methods, such as SVM, GA, Principal Component Analysis (PCA), and Bayesian regression; b) fault detection based on the definition of a failure index, i.e. a failure index describes the variation of bridge behaviours; $c$ ) unsupervised clustering methods for fault detection.

\section{a) Fault detection using machine learning and statistical methods}

In this section fault detection methods that rely on the performance of statistical and machine learning strategies are presented. Particularly, a fault detection method based on a GA optimization research is presented by [He et al, 2011]; a PCA-based method is presented by [Bellino et al., 2010; Cavadas et al., 2013; Laory et al., 2013]; a fault detection based on a Bayesian regression approach presented by [Kim et al., 2015] and, a SVM fault detection method [Ren et al., 2013] are also discussed. Table 6 shows the main characteristics of the these works.

\begin{tabular}{|c|c|c|c|c|}
\hline Reference & Type of bridge & Fault detection method & Type of input data & Results \\
\hline He et al, 2011 & $\begin{array}{c}\text { FE model of a steel } \\
\text { girder bridge }\end{array}$ & Genetic algorithm & Vibration of the bridge & $\begin{array}{c}\text { Analysed patterns are } \\
\text { correctly identified }\end{array}$ \\
\hline Kim et al., 2015 & Seven-span plate bridge & Bayesian regression & $\begin{array}{c}\text { Acceleration of the } \\
\text { bridge }\end{array}$ & $\begin{array}{c}\text { Depends on the } \\
\text { environmental } \\
\text { conditions, such as } \\
\text { traffic load }\end{array}$ \\
\hline
\end{tabular}




\begin{tabular}{|c|c|c|c|c|}
\hline Bellino et al., 2010 & $\begin{array}{c}\text { Laboratory model of } \\
\text { simple supported bridge }\end{array}$ & $\begin{array}{c}\text { Principal component } \\
\text { analysis }\end{array}$ & $\begin{array}{c}\text { Natural frequencies of } \\
\text { the bridge }\end{array}$ & $\begin{array}{c}\text { Depends on the noise of } \\
\text { the input data. Good } \\
\text { results with low noise. }\end{array}$ \\
\hline Ren et al., 2013 & $\begin{array}{c}\text { FE model of a truss } \\
\text { bridge }\end{array}$ & Support vector machine & $\begin{array}{c}\text { Maximum deflection of } \\
\text { the bridge }\end{array}$ & $\begin{array}{c}\text { Accuracy from 93\% to } \\
99 \% \text { depending on the } \\
\text { level of the noise of the } \\
\text { input data }\end{array}$ \\
\hline Cavadas et al., 2013 & Concrete frame bridge & $\begin{array}{c}\text { Moving Principal } \\
\text { component analysis and } \\
\text { Robust regression } \\
\text { analysis }\end{array}$ & $\begin{array}{c}\text { Moving Principal } \\
\text { component analysis has } \\
\text { shown good detection of } \\
\text { faults, whereas Robust } \\
\text { regression analysis has } \\
\text { good results only with } \\
\text { specified input data. }\end{array}$ \\
\hline Laory et al., 2013 & $\begin{array}{c}\text { Steel truss railway } \\
\text { bridge }\end{array}$ & $\begin{array}{c}\text { Moving Principal } \\
\text { component analysis } \\
\text { coupled with regression } \\
\text { methods }\end{array}$ & Five spans box girder \\
bridge & $\begin{array}{c}\text { The coupling of MPCA } \\
\text { and regression methods } \\
\text { shows better results than } \\
\text { the singular methods. }\end{array}$ \\
\hline
\end{tabular}

Table 3. Fault detection methods using machine learning and statistical methods algorithms.

[He et al., 2011] have proposed a direct analysis of the train-induced bridge vibration data. The authors presented a fault detection method, which has used prior assumed fault patterns of the bridge members as input data. If the train-induced dynamic responses of the bridge under a certain damage pattern was identical, or very close, to one of the prior assumed fault patterns, the fault could be identified. An FE model of a simply supported steel girder bridge was considered. A GA has been adopted to find the exact damage pattern, where the objective function has been defined as the difference between the calculated train-induced bridge response and the prior assumed fault patterns. Different failure scenarios have been analysed; results showed that the input unknown fault scenarios have been identified for all cases. However, if the bridge was failed but its measured response did not belong to the a priori simulated failures scenarios, the bridge was declared to be in a good state, whilst in reality it was in a failed state. [Kim et al., 2015] developed a 3-step procedure: $i$ ) an autoregressive model has been developed using bridge acceleration measurements, and then the autoregressive coefficient has been defined as the damage indicator; $i i)$ a Bayesian regression analysis of the selected damage indicators has been carried out using online updating; iii) residuals between the observed and predicted damage indicators have been computed, and a decision on the bridge health state could be made accordingly. The proposed method has been tested using acceleration data over one year, measured on a seven-span plate-Gerber bridge, which was in a healthy state. Three different data strategies have been considered: $a$ ) complete environmental change scenario, where acceleration, temperature and vehicle weight data have been used; $b$ ) temperature change scenario, where acceleration and temperature data have been used; $c$ ) no environmental change scenario, where only acceleration data without considering environmental changes have been used. Results showed that the analysis, considering both temperature and vehicle weight as environmental effects (case $a$ ), led to more accurate results than case $b$ ) and $c$ ). It should be noted that a more accurate and reliable assessment of the bridge health state is achieved when not only the behaviour of the bridge (e.g. acceleration) is considered in the analysis, but also the changes of environmental condition. Therefore, this confirms the idea that a comprehensive SHM method should consider the influence of the environmental effects on the health state of the bridge. Finally, the decision making process on the bridge health state has been demonstrated; its results showed that, except for only one case, 
all studied recorded data has been successfully classified as belonging to behaviour of a bridge in a healthy state. In this method, the environmental effects have been considered, and it has been demonstrated that more accurate results can be achieved by considering the effect of environmental condition on the health state of the bridge. [Bellino et al., 2010] have studied a fault detection method based on PCA in order to remove the dependence of natural frequencies data from the effect of external factors, such as the mass and the velocity of a train, which was passing over a bridge, to focus the fault detection only on the structural characteristics of the bridge. The healthy state of the bridge has been defined using a damage index, called the novelty index, which is based on the Mahalanobis norm [Brereton, 2015]. Natural frequencies have been selected as features for the fault detection. A simply supported beam has been considered as bridge model, and different failures have been simulated. Results showed that the beam failures have been successfully detected by using the Mahalanobis-based damage index if the noise of the data was not too high (less than $3 \%$ of the magnitude of data). It is worth mentioning that during the PCA, information can be lost. Furthermore, the environmental condition are not negligible in assessing the health state of the bridge. [Ren et al., 2013] presented a fault detection method based on SVM. A FE model of a simple supported steel truss bridge has been developed and analysed. The SVM method has been fed with the bridge maximum deflection, which has been measured in 7 different places. Five different load examples have been considered in order to simulate different trains over the bridge, and 7 levels of noise have been added to the data. Results showed that the proposed method was able to identify the location and the severity of failures with good accuracy. However, if the level of noise increased, the accuracy decreased, e.g. accuracy dropped from 99\% (with no added noise) to $93 \%$ (with a $10 \%$ of noise). [Cavadas et al., 2013] developed a fault detection method based on bridge moving-load data of regular traffic by adopting two data-driven methods: a Moving PCA (MPCA) and a Robust Regression Analysis (RRA). Influence lines of the simple concrete frame bridge have been used as input of the two data-driven methods. Two time series data have been built by using the influence line of the bridge: the former considered the whole influence line, whereas the latter considered only the influence line at given load position. Both data-driven methods, MPCA and RRA, were firstly trained using data of the healthy bridge structure in order to set an appropriate failure threshold, and then, data of a simulated failure was used as input of the MPCA and RRA in order to be analysed. Results showed that the MPCA allowed an early detection of the simulated failure by using both time series data. On the other hand, RRA has been demonstrated to provide good results with data considering the whole influence line, whereas, reliable results have been obtained by RRA using time series data based on influence line at a given load position. It is worth highlighting that environmental conditions were not considered, and furthermore, only the identification of the failure existence has been carried out using the proposed method. Therefore, the fault detection analysis was not comprehensive. Finally, [Laory et al., 2013] developed a fault detection method by coupling MPCA and regression methods, such as RRA. The method has been applied to an FE model of a steel truss bridge, which has been damaged by reducing the stiffness of axial members. The performance of the MPCA-RRA method was compared with those of the individual methods, and the results showed that the proposed method had better performance in terms of damage detectability. The method was also tested on a real five-span box girder bridge. Again, the results of the proposed method were better of those of the individual methods. Although the 
method showed good performance, the main results were based on an FE model, due to the fact that the five-span bridge case study was based on only few measurements, which were collected during the building phase of the bridge. Furthermore, the method is not vibration-based, i.e. the inputs to the model are quasi-static measurements rather than the vibration characteristics of the bridge, where the latter have been demonstrated to be more sensitive to failures.

\section{b) Fault detection based on the definition of a failure index}

The monitoring of the bridge characteristics, such as acceleration, displacements and natural frequencies, can point out unexpected bridge behaviours even without developing a mathematical method that is able to analyse the bridge characteristics. Indeed, the health state of the bridge can be monitored by simply defying a fault index, which, for example, can be based on the variation of the displacements (or natural frequencies, acceleration, etc.) of the bridge, and monitoring its variations over time, as shown by [Sun et al., 2015] and [Zhan et al., 2011]. [Fan et al., 2011] also present a comparative study between two fault detection methods based on failure index definition and three response-based methods. Finally, the health condition of the bridge can be also assessed by monitoring the evolution of the bridge modal parameters [Gentile et al., 2015]. Table 7 shows the main characteristics of these works.

\begin{tabular}{|c|c|c|c|c|}
\hline Reference & Type of bridge & Fault detection method & Type of input data & Results \\
\hline Sun et al., 2015 & $\begin{array}{c}\text { Multi steps method } \\
\text { model of a truss bridge } \\
\text { based on vertical and } \\
\text { horizontal modes of the } \\
\text { structure }\end{array}$ & $\begin{array}{c}\text { Acceleration of the } \\
\text { bridge }\end{array}$ & $\begin{array}{c}\text { Tested failure scenarios } \\
\text { are correctly identified. }\end{array}$ \\
\hline Zhan et al., 2011 & $\begin{array}{c}\text { FE model of three-span } \\
\text { bridge }\end{array}$ & $\begin{array}{c}\text { The variation of a fault } \\
\text { index based on natural } \\
\text { frequencies and } \\
\text { damping ratio }\end{array}$ & $\begin{array}{c}\text { Displacements and } \\
\text { natural frequencies of } \\
\text { the bridge }\end{array}$ & $\begin{array}{c}\text { Fault index is able to } \\
\text { detect unexpected } \\
\text { bridge behaviours. }\end{array}$ \\
\hline Fan et al., 2011 & FE model of a simple \\
cantilever beam & $\begin{array}{c}\text { The model based SDI } \\
\text { method }\end{array}$ & $\begin{array}{c}\text { Natural frequencies of } \\
\text { the bridge }\end{array}$ & $\begin{array}{c}\text { Suitable only for single } \\
\text { failures. }\end{array}$ \\
\hline Gentile et al., 2015 & Arch trussed bridge & $\begin{array}{c}\text { Mode shapes and } \\
\text { Natural frequencies } \\
\text { monitoring }\end{array}$ & $\begin{array}{c}\text { Acceleration of the } \\
\text { bridge }\end{array}$ & $\begin{array}{c}\text { The degraded elements } \\
\text { of the bridge have been } \\
\text { identified. }\end{array}$ \\
\hline
\end{tabular}

Table 4. Fault detection methods using a failure index.

[Sun et al., 2015] presented a multi-level fault detection strategy using natural frequencies and mode shapes of the structure, which have been obtained by manipulating the bridge acceleration data, retrieved by Wireless Sensors Network (WSN). Particularly, the acceleration data of the bridge are used as the input to a Fast Fourier transform, and, therefore, the natural frequencies are obtained by looking for the peak of the amplitude spectral density, whereas the mode shapes are provided by the singular value decomposition of the cross spectral density matrix [Araújo and Laier, 2014]. An FE model of a full-scale truss structure has been developed and four different fault scenarios have been simulated. In the first step of fault detection procedure, the fault location was successfully identified by pointing out the truss bay of the failure and using a fault index based on vertical modes. In the second step of the proposed procedure, a new fault index based on both vertical and horizontal modes was defined in order to identify the exact location of the failure. Results showed that the faulty element has been 
successfully identified in all simulated scenarios. However, when the method was applied to a laboratory case study, some false alarms have been raised. Further false alarms could occur, if the method was applied to a real bridge case study, as the method currently does not account for the influence of the environmental effects on the bridge behaviour. [Zhan et al., 2011] have developed a fault detection method based on a fault index, which has been defined considering natural frequencies and damping ratio. A multistep iterative process has been developed in order to detect the presence of failures in a three-span continuous bridge. At each step of the iteration, the fault index was updated by using the difference between predicted (by an FE model) and measured displacement. Single and multiple failure scenarios have been considered and a train, which was passing over the bridge, was simulated. Results showed that the fault location has been identified correctly. However, the authors acknowledged the fact that the proposed fault detection method can be used for the studied case (i.e. the same model of train, the same velocity of train, etc.) only, and that the environmental effects (such as wind and temperature) have to be considered, in order to maintain the fault detection accuracy. [Fan et al., 2011] performed a comparative study of fault detection methods based on a simple FE cantilever beam model. Five different fault detection algorithms based on different modal parameters have been compared: $i$ ) a Single-Damage-Indicator (SDI) methods, which is based on the changes of the natural frequencies between before and after the failure; $i i)$ a responsebased method (called GFD), using the fundamental mode shapes of the faulty beam; iii) a response-based method (called MSC), using mode shape between before and after the failure; $i v$ ) a response-based method (called GSM), using the mode shape curvature of the faulty beam; v) a Damage-Index-Method (DIM), using the mode shape curvatures of the faulty beam. Considering the performance of the methods in detecting single and multiple failures, authors have demonstrated that single failures are successfully detected by all methods, whereas, multiple failures are correctly identified only by MSC, GSM and DIM models (the SDI method is derived from, and designed for, a single failure occurrence assumption; the GFD sensitivity highly depends on the failure location). Finally, [Gentile et al., 2015] developed an SHM method by relying on an automated modal identification method, which was performed using a frequency domain decomposition method, in order to assess the change of the natural frequencies and mode shapes of an arch truss railway bridge. Results have shown that the frequency of the bridge dropped suddenly in the location of the degraded component. However, it is worth noting that the modal characteristics of the bridge are usually strongly influenced by changing environmental conditions, and consequently this phenomenon need to be accounted for in the SHM method. For example, for the same railway bridge [Cabboi et al., 2014] proposed a prediction regression model in order to predict the natural frequencies of the bridge under changing environmental conditions.

\section{c) Unsupervised clustering methods for fault detection}

As it has been pointed out in section 3.2.1.3, a major limitation of machine learning methods is the training process, which requires a database of bridge behaviours in order to train the model in predicting or classifying the future behaviour of the bridge. Furthermore, the health state of the bridge can also be assessed by using unsupervised methods, by usually adopting 
clustering techniques [Martins et al., 2007]. Indeed, clustering algorithms aim to group the different behaviours of a bridge by maximizing the between-cluster variance, i.e. different bridge behaviours are grouped in separate and well distanced clusters, with the aim of maximizing the distance among these different clusters. At the same time, however, the clustering methods aim to group behaviours of the bridge that have similar properties by minimizing the within-cluster variance. In this way, the measured behaviours of the bridge can be grouped and analysed based on their characteristics, and unexpected bridge behaviours can be identified by analysing the statistical nature of the measured data. For example, unsupervised clustering techniques have shown to effectively assess the health state of wind turbine blades [Hoell et al., 2017], components of a nuclear power plant [Baraldi et al., 2015] and a control system of industrial systems [Yan et al., 2016]. Table 8 shows the most relevant characteristic of the unsupervised clustering methods that are discussed in this section.

\begin{tabular}{|c|c|c|c|c|}
\hline Reference & Type of bridge & Clustering method & Type of input data & Results \\
\hline Cury et al., 2012 & Steel bridge & $\begin{array}{l}\text { Hierarchy-divisive and a } \\
\text { dynamic clouds } \\
\text { clustering methods }\end{array}$ & $\begin{array}{c}\text { Symbolic acceleration, } \\
\text { natural frequencies and } \\
\text { mode shapes }\end{array}$ & $\begin{array}{l}\text { Good assessment of the } \\
\text { health state of the bridge } \\
\text { with very low false } \\
\text { alarms raised. }\end{array}$ \\
\hline Guo et al., 2012 & Steel bridge & K-means clustering & Sorted acceleration data & $\begin{array}{l}\text { Good performance in } \\
\text { the analysis of the FE } \\
\text { model. However, false } \\
\text { alarms are raised in the } \\
\text { analysis of the real } \\
\text { bridge. }\end{array}$ \\
\hline Langone et al., 2017 & Concrete bridge & $\begin{array}{c}\text { adaptive kernel spectral } \\
\text { clustering }\end{array}$ & Natural frequencies & $\begin{array}{l}\text { Good detection ability } \\
\text { of the method, that } \\
\text { decrease as the } \\
\text { environmental condition } \\
\text { changes. }\end{array}$ \\
\hline Silva et al., 2016 & Concrete bridge & $\begin{array}{l}\text { Genetic Algorithm for } \\
\text { Decision Boundary } \\
\text { Analysis-based } \\
\text { clustering method }\end{array}$ & Natural frequencies & $\begin{array}{l}\text { Ability to identify the } \\
\text { failure of the bridge } \\
\text { structure even under } \\
\text { sever environmental } \\
\text { conditions. }\end{array}$ \\
\hline Alves et al., 2016 & $\begin{array}{l}\text { Steel railway bridge and } \\
\text { concrete highway bridge }\end{array}$ & $\begin{array}{l}\text { K-means, hierarchy- } \\
\text { agglomerative and fuzzy } \\
\text { c-means clustering } \\
\text { methods }\end{array}$ & Acceleration data & $\begin{array}{l}\text { Good results for the } \\
\text { railway bridge. Many } \\
\text { misclassification for the } \\
\text { highway bridge due to } \\
\text { changing environmental } \\
\text { condition. }\end{array}$ \\
\hline
\end{tabular}

Table 5. Fault detection methods using a failure index.

[Cury et al., 2012] proposed a comparison between a hierarchy-divisive and a dynamic clouds clustering methods. A steel railway bridge, which was subjected to a strengthening process, was considered as a case study. The measurements of the acceleration and natural frequencies of the bridge before and after the strengthening procedure, which were transformed into symbolic data by the means of a frequentist analysis, were used as the input to the analysis. When a new measurement of the bridge acceleration was available, it was assigned to the cluster with the minimum distance. Results showed a very low rate of misclassification, and that a new cluster was mainly defined by using the acceleration data as the input to both clustering methods. Therefore, a new and unexpected behaviour of the bridge was pointed out. However, when the analysis was performed by using the natural frequencies as the input to the 
clustering methods, the new measurements were mainly assigned to the cluster, representing the bridge before the strengthening process. Therefore, the method can be used for fault detection purposes, even if the change of the bridge behaviour, due to the influence of the environmental condition, can lead to some misclassifications. A similar approach, with the aim of using raw acceleration data in order to carry out an unsupervised structural failure detection analysis by the means of clustering techniques, has been presented in [Alves et al., 2015b] for a steel beam and a highway bridge. Therefore, it is worth noting that an SHM method, which is developed and verified on a particular case study, can then be applied to a different case study by adapting the parameters of the SHM method to the behaviour and environmental condition of the new case study. In a similar way, [Guo et al., 2012] presented a K-meansbased clustering method in order to assess the health state of a steel railway bridge, by analysing its acceleration. A PCA analysis was used in order to filter the acceleration data, by reducing the influence of the temperature on the measured data. Then, the K-means algorithm was used in order to group the measured data into different groups, and to evaluate the distance among the different clusters. The methods showed good performance in identifying failures when an FE model was adopted, however, when a real steel railway bridge was analysed, several false alarms were raised. [Langone et al., 2017] presented an unsupervised adaptive kernel spectral clustering in order to monitor the health state of bridge infrastructure. The method was applied to a real-time monitoring process of a concrete bridge that was damaged artificially. Results showed that after a calibration phase, that aimed to tune the parameters of the clustering algorithm, the failure of the bridge was identified correctly by the proposed method. However, when the environmental conditions changed, for example, the bridge was monitored during winter, the accuracy of the proposed method decreased. [Silva et al., 2016] developed a Genetic Algorithm for Decision Boundary Analysis (GADBA)-based clustering method in order to detect failures of a concrete bridge, which has been artificially damaged. The GADBA algorithm was used in order to identify the best centroids of each possible cluster. Results showed that the method was able to identify the failures that were introduced in the bridge and, particularly, the method was robust with respect to the environmental condition changes. For example, the monitoring process of the bridge went through some severely cold days that have influenced the behaviour of the bridge. The proposed method did not raise a false alarm during these days. However, the method aimed to respond only to the first step of the four requirements of the fault detection process, i.e. the identification of the failure existence is considered. Finally, [Alves et al., 2016] presented a study in order to compare the performance of three clustering algorithms, K-means, hierarchy-agglomerative and fuzzy c-means clustering methods, in two different case studies: a steel railway bridge and a concrete highway bridge. The symbolic values of the acceleration data measured directly in situ were used for the analysis, i.e. without performing any data pre-processing, the acceleration data were transformed into symbolic variable by the means of a frequentist analysis. The three methods showed good results when the steel railway bridge was analysed, where the K-means algorithm outperformed the other methods in identifying the changes of the stiffness of the bridge. In this case study, however, the changes of the environmental conditions were not considered. On the other hand, the analysis of the highway bridge showed that the fuzzy c-means method was able to provide the best classification results by correctly identifying the behaviour of the bridge before and after the change of the stiffness. In this case study, however, the changing 
environmental conditions led to a high number of misclassification (over 40\%). The authors also tried to reduce the uncertainties due to effects of the environmental conditions by considering a smaller batch of data, however, the performance of the clustering methods improved only slightly.

\subsubsection{Discussion on other non-model-based methods}

The presented non-model-based methods have demonstrated the ability to detect failures in the considered case study efficiently. However, false alarms and misclassification were obtained. [Kim et al., 2015] have pointed out that the understanding of how ambient temperature and traffic effects should be considered in long-term bridge health monitoring stress is of vital importance, but such environmental conditions are generally not considered by many authors. Therefore, it is worth noting that implementing modal based fault detection algorithms on real world structures can lead to many false alarms due to the impact of environmental variations on the modal properties, which are usually not considered. The non-model-based methods are usually optimized for specified structure that are subject to known environmental and operational conditions. Therefore, good performance for new and previously unknown environmental and operational conditions, which have been not included in the database used to train the method, cannot be guaranteed [Zio, 2012]. It is worth mentioning that the methods presented in this section are mainly focused only on the first two requirements of the fault detection process, i.e. failure existence and failure location. Therefore, the magnitude of the failure and the assessment of the RUL of the bridge, by predicting the future condition of the bridge, are not assessed. The main reason for this is that in order to assess the magnitude of a failure and to predict the health state of the bridge under future condition, non-model-based methods require to be trained with similar behaviour, and consequently, a vast database that contains both healthy and degraded behaviours of the bridge is needed. At the same time, some of the non-model-based methods, such as SVM, MPCA and clustering techniques, are able to assess the magnitude of failure if they are tuned in with some behaviours of the bridge that are similar to the actual failed (degraded) bridge behaviour, and furthermore, these non-modelbased methods are not able to predict future behaviour of the system. Finally, the influence of individual components on the health state of the whole bridge is also not considered by these methods.

\subsubsection{Bayesian Belief Networks}

In structural engineering framework, the BBN method has been mainly used in reliability assessment studies. BBNs have been developed in the 80s, when a novel approach to represent the expert knowledge within a computational architecture has been proposed by [Pearl, 1986]. In that work, Pearl developed a graphical interface between expert knowledge, statistics and computers, by linking nodes, which represent the object under study and its properties. The theoretical background of BBNs is presented in [Mast et al., 1999; Jensen \& Nielsen, 2007]. Indeed, failure of a bridge may have serious consequences on human life and on the environment and, thus, in order to support a robust decision-making process, the probability of 
failure has to be assessed. For instance, [Salamatian et al., 2013] have demonstrated that BBNs are able to adequately assess the probability of failure of a bridge due to the scour phenomenon. In fact, they show how BBNs can manage complex interactions between system parameters, as those involved in the assessment of the bridge safety against scour. Furthermore, [Franchin et al., 2016] presented a BBN study to predict the fragility of the reinforced concrete bridges, showing how the BBN can easily merge expert judgement and dataset information. In addition, the authors highlighted the efficacy of the BBN in accounting for different uncertainties, i.e. uncertainties due to the incomplete knowledge of the phenomenon (i.e. epistemic uncertainties) and to the aleatory of the events (i.e. aleatory uncertainties). The BBN has been also used to assess technical causes of a catastrophic bridge downfall [Holický et al., 2013]. In their work, Holický et al. showed how the BBN could be used to manage complex information from different technical fields, such as those available in the forensic engineering assessment. The $\mathrm{BBN}$ has been demonstrated to be able to divide a complex problem into smaller sub-tasks, which have been studied separately, retrieving an assessment of the relative significance of individual causes, contributing to the bridge collapse. BBN could be a good candidate for SHM purposes as it gives the opportunity to assess the health state of bridge components and the whole bridge at the same time, and to predict future health states [Rafiq et al., 2015].

\subsubsection{BBN studies for bridges}

The use of the BBN methods in the SHM of railway bridge framework is limited. However, BBN-based methods can be a great candidate for the real time SHM, as they can provide an assessment of the bridge health state, every time when new evidence becomes available. The BBN method strongly depends on the definition of the CPTs, which can be defined using datasets and simulation model of the bridge under study, or relying on expert judgement, based on past observation, knowledge and experience. However, the expert opinion can be subjective. Furthermore, an extension of the BBN, called Dynamic Bayesian Network (DBN), may be used to analyse problems with time varying domains. Table 9 shows the main characteristic of the BBN-based discussed in this section, by highlighting the type of the bridge and the SHM method proposed by the authors, the definition of the CPTs that is one of the most critical issues of the BBNs and the type of data used as input of the BBN.

\begin{tabular}{|c|c|c|c|c|c|}
\hline Reference & Type of bridge & Proposed method & Definition of CPTs & Type of input data & Results \\
\hline Rafiq et al., 2015 & $\begin{array}{c}\text { 50 Masonry arch } \\
\text { bridge } \\
\text { modelling of the } \\
\text { bridge based on } \\
\text { BBN and DBN } \\
\text { methods }\end{array}$ & Expert judgment & $\begin{array}{c}\text { Bridge visual } \\
\text { inspection results } \\
\text { (SCMI) }\end{array}$ & $\begin{array}{c}\text { Condition of the } \\
\text { bridge over time }\end{array}$ \\
\hline $\begin{array}{c}\text { Attoh-Okine \& } \\
\text { Bowers, 2006 }\end{array}$ & $\begin{array}{c}\text { Single span steel } \\
\text { girder, reinforced } \\
\text { concrete deck } \\
\text { bridge }\end{array}$ & $\begin{array}{c}\text { Deterioration } \\
\text { modelling of the } \\
\text { bridge based on } \\
\text { BBN }\end{array}$ & Expert judgment & Expert judgment & $\begin{array}{c}\text { Probability of the } \\
\text { bridge health state }\end{array}$ \\
\hline Wang et al., 2012 & Girder steel bridge & $\begin{array}{c}\text { Condition } \\
\text { modelling of the } \\
\text { bridge based on } \\
\text { DBN }\end{array}$ & Expert judgment & $\begin{array}{c}\text { Simulated } \\
\text { observations of the } \\
\text { bridge }\end{array}$ & $\begin{array}{c}\text { Condition of the } \\
\text { bridge over time }\end{array}$ \\
\hline
\end{tabular}




\begin{tabular}{|c|c|c|c|c|c|}
\hline Zonta et al., 2007 & $\begin{array}{c}\text { Precast reinforced } \\
\text { concrete bridge }\end{array}$ & $\begin{array}{c}\text { Fault detection } \\
\text { based on Bayesian } \\
\text { method }\end{array}$ & $\begin{array}{c}\text { Total ignorance a } \\
\text { priori }\end{array}$ & Strain of the bridge & $\begin{array}{c}\text { Position of the } \\
\text { failure has been } \\
\text { identified }\end{array}$ \\
\hline Lebeau et al., 2010 & $\begin{array}{c}\text { Prestressed } \\
\text { concrete bridge }\end{array}$ & $\begin{array}{c}\text { Fault detection } \\
\text { based on BBN }\end{array}$ & $\begin{array}{c}\text { Expert judgment } \\
\text { and experimental } \\
\text { results }\end{array}$ & $\begin{array}{c}\text { Historical database } \\
\text { of visual inspection }\end{array}$ & $\begin{array}{c}\text { Probability of the } \\
\text { bridge failure over } \\
\text { time }\end{array}$ \\
\hline
\end{tabular}

Table 6. BBN methods described in this section.

[Rafiq et al., 2015] showed how a BBN method could be used as a condition-based deterioration modelling methodology for a bridge management system. The data used as the input to the BBN model were the inspection results, i.e. the Structures Condition Marking Index (SCMI) [Network Rail, 2004] score, obtained from the inspection of 50 masonry arch railway bridges. The distribution of the health state of the whole bridge was obtained using the BBN: the bridge condition depends on the condition of its major elements (deck and support condition), and the way the major elements depend on the health state of the minor elements reflects the relative importance of minor elements in defining the condition of a major element. Then, the deterioration profiles for the masonry arch group bridge were obtained, using DBN to account for the time dependent characteristics. The relationships between the variables in successive times were expressed through conditional probabilities for the temporal links (also known as transition probabilities) [Weber et al., 2003; Straub, 2009; Gu et al., 2010]. The transition probability between future SCMI intervals (good - SCMI > 80, fair - SCMI >45, poor - SCMI < 45) was quantified using a Markov chain. Furthermore, the transition interval was set to be equal to 6 years, as this was the frequency of visual inspections considered in this study. Although the results showed the deterioration of the bridge condition over a six year period, the assessment of current condition of the bridges was not performed, and moreover, the method was based on visual inspection reports, which can be subjective. Finally, environmental conditions and the monitoring of the structural behaviour of the bridge over time were not considered. [Attoh-Okine \& Bowers, 2006] built a BBN using a Fault Tree (FT) for a railway bridge [LeBeau et al., 2010]. The deterioration of the bridge performance was influenced by the condition of the deck, superstructure and substructure, which in turn were influenced by the condition of the joints, the deck materials, the girders and the bearing, and the abutments, respectively, as shown in Fig. 4.

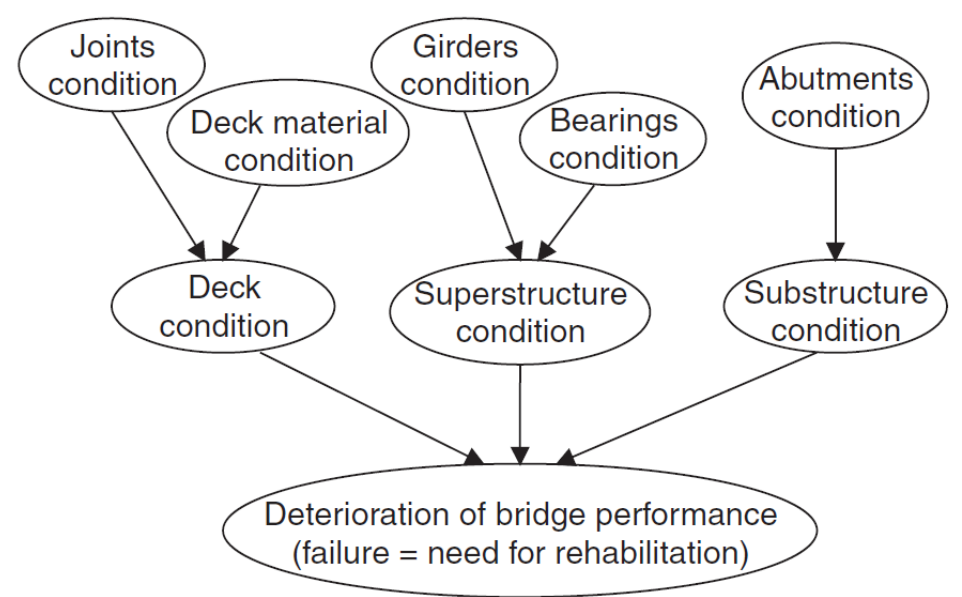

Fig. 1. A BBN model of a railway bridge. 
The input data to the $\mathrm{BBN}$, i.e. the probabilities of bridge minor elements being in one of its possible states, were obtained by interviewing seven bridge engineers and inspectors. The CPTs for the overall bridge deterioration process were described by using engineering judgment. The probability of the overall bridge condition and of the intermediate child nodes has been demonstrated to change significantly once a new condition of the parental nodes (minor elements) is assumed. It should be noted that the authors presented a qualitative case study in order to investigate the feasibility of SHM by using a BBN method, and consequently, the behaviour of the bridge was not simulated and considered in the analysis. [Wang et al., 2012] proposed the DBN to predict the condition of bridge elements. The deterioration process of bridge elements was modelled using a discrete-time Markov process and, maintenance actions, environmental effects (i.e. traffic volumes and loads, temperature, humidity) and new evidence of the bridge behaviour were used as DBN input at each time step. The main girder of a steel railway bridge has been studied and the evolution of its condition over 100 years has been predicted. The CPTs were estimated using the expertise knowledge. Three different scenarios, over the next 100 years of the bridge life, have been compared: $i$ ) a perfect maintenance action has been simulated to be performed after 50 years of bridge life; ii) no maintenance and visual inspection actions have been carried out over the 100 years of the bridge life; iii) visual inspections have been carried out every 5 years in the first 20 years of the bridge life. The analysis results showed how the evolution of the bridge condition changes significantly, when new bridge condition information, i.e. the visual inspection records, became available. Despite the promising results of the method in predicting the health state of the bridge in the future, the monitoring of the structural behaviour of the bridge is not considered in the method. Therefore, the fault detection analysis cannot be carried out using the presented method. [Zonta et al., 2007] presented a condition monitoring strategy using a fault detection algorithm, based on Bayesian analysis, and applied it to a precast reinforced concrete bridge. The authors simulated an instrumented bridge, in which the sensors analysed both structural and environmental effects. The Bayesian updating was performed by the calculation of the probability of being in each studied scenario, once a new day measurement was available. A priori total ignorance was assumed by assuming equal probability for the healthy and faulty state of the bridge. On one hand, the results of the proposed method showed that the simulated fault position has been detected. On the other hand, the method was not able to identify the time occurrence of the simulated failure, and the environmental conditions and the magnitude of the failure were not considered in the analysis. The BBN has also been used to evaluate the impact of deterioration mechanism in a bridge element, as shown by [Lebeau et al., 2010], using a bridge load rating analysis, i.e. a measure of bridge live load capacity that permits safe utilization of the bridge. Using historical database and comparing the BBN results with 4 visual inspection reports, which have been carried out during 42 years of bridge life, the probability of failure of the inventory load rating test has been detected to increase with time and, thus, inspections and maintenance programs could have been adopted in a different way to minimize this increase. Finally, a diagnosis of the increasing in the probability of failure of the inventory load-rating test has been performed, and the prestressing steel area has been found to be the variable, which is mostly influenced by deterioration and corrosion mechanism. It is worth noting that the method did not focus on the monitoring of the health state of the bridge by analysing the structural behaviour of the bridge, but rather on the analysis of how different 
maintenance techniques influenced the health state of the bridge. However, the influences among different elements of the bridge were assessed, and consequently, this approach can be used in order to evaluate how the health state of different bridge elements can be influenced by the health state evolution of a degraded bridge element.

\subsubsection{Discussion on BBN methods}

Generally, the BBN method describes the deterioration process of the bridge by considering the effects of each individual bridge element on the health state of the whole bridge. BBN can also address the problem of lack of considering uncertainties, which was present in the methods showed in the previous sections, by merging expert knowledge and bridge response data, and consequently the results of the BBN rely on the strength of the expert knowledge and the comprehensive information regarding the behaviour of the bridge. However, the structural behaviour of the bridge is usually not considered as the input to the presented BBN methods. Instead, visual inspection reports, SCMI scores and assumed health state of bridge components are used as evidence of the bridge behaviour. The prior probability distribution is one the major issues of the Bayesian theory. The usual practice is to use expert opinion regarding some reliability characteristics [Coolen, 1992; Coolen, 1996]; also, a meta-analysis can be used to quantify prior information in terms of distributions [Gelman et al., 1996], or a data-based prior distribution construction [Guikema, 2007]. Finally, if no useful prior information is available, a non-informative prior or its proper approximation, which expresses general information about quantities of interest, can be adopted [Berger et al., 2004]. The size of the CPT is another issue, as it can increase considerably with the number of parents, which can make the process of populating the CPTs intractable. This problem can be avoided using fewer states for each node and the divorcing node technique [Chen \& Pollino, 2012].

Although the environmental effects have been considered in the case studies of the BBN method as an important factor that influences the health state of the bridge, further development of BBN methods for SHM are needed in order to respond to the SHM desiderata and to achieve an automatic fault detection and SHM methods, which responds to the scheme shown in Fig. 1.

\section{A short-span steel railway bridge: a comparative study}

In this section, a short-span steel structure of a railway bridge (Fig. 5) is considered in order to describe and compare the different types of SHM approaches that have been reviewed in this paper. The aim of this section is to illustrate how the different condition monitoring and fault detection methods can be used during the life cycle of the bridge, in order to monitor the evolution of the health state of the bridge over time. A short-span steel bridge is selected due to the fact that short-span bridges are one of the most common structures for railway bridges, and their degradation mechanisms, such as corrosion and cracks, can develop rapidly, once they have been initiated [Chen et al., 1999; AISI, 2007; Psimoulis et al., 2013; Yan et al., 2015; Nour et al., 2016; Rocha et al., 2016]. Furthermore, it is worth mentioning that the behaviour 
of a short-span railway bridge is strongly influenced by the dynamic characteristics of the track and the dynamic properties of the train that is passing over the bridge [Rocha et al., 2012]. Therefore, the measurement of the bridge behaviour due to external disturbances, such as traffic or environmental effects, is a difficult task, as the noise can cover the vibration properties of the bridge. Hence, usually an adequate pre-processing of the measured behaviour of the bridge is required, in order to assess the health state of the bridge correctly.

The SHM strategies, which have been presented and discussed in the previous sections, are hereafter analysed with respect of a health monitoring process of a short-span steel structure of a railway bridge. Advantages and disadvantages of each method are then discussed and compared.

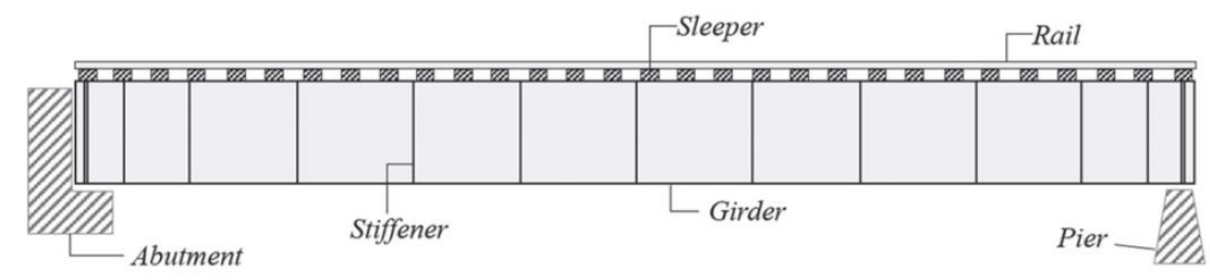

Fig. 5. Schematic of a steel railway bridge [Feng et al., 2015].

\subsection{Structural health monitoring of a short-span steel railway bridge strategy}

In Section 2, the desiderata of a SHM method are introduced by pointing out that a real-time monitoring strategy of the structure is needed, in order to identify early signs of failure and schedule the maintenance accordingly by reducing the whole life cycle cost of the bridge. A mathematical method, which monitors the health state of the bridge, should be able to automatically, remotely and rapidly assess the bridge health state, by distinguishing between actual changes to the bridge health state and those due to changes in environmental conditions. Furthermore, it is worth noting that the health state of a bridge is influenced by the health state of its elements, such as beams, deck slab, abutments, etc., and consequently the health state of each element of the bridge should be assessed simultaneously. Following these requirements, the SHM of a short-span steel railway structure can be performed as follows, by describing the application of each SHM strategy to a real railway short-span bridge in order to discuss the advantages and disadvantages of each SHM method:

- FE model updating. [Feng et al., 2015], for example, proposed an updating strategy for a short-span steel railway bridge in the US. The bridge was monitored using a videocamera in order to assess the displacement of the bridge under trainloads. The FE model was developed by following the design drawings of the bridge. The equivalent stiffness of the bridge was selected as the updating parameter, after that a sensitivity analysis was performed. The updating strategy of the FE model, which aimed to optimize an 
objective function based on the differences between simulated and measured dynamic displacement of the bridge, led to a model that was able to reach a good agreement with the actual displacements of the real bridge.

- Advantages. An FE model can be applied even to a new bridge, where the measurements of the bridge behaviour are not yet available or are very limited. Indeed, the FE model can be developed during the design phase of the bridge in order to design and plan the construction of the bridge, in the optimal and safest way [Yan et al., 2015]. The FE model can simulate the behaviour of each element of the bridge, and therefore, the influence among different degrading elements of the bridge can be assessed. Furthermore, the FE model can also predict the future behaviour of the bridge, if it is coupled with a mathematical model that describes the evolution of the degradation of the bridge material over time, such as the growth of cracks [Corbetta et al., 2015; Attema et al., 2017] or the evolution of the corrosion [Kreislova et al., 2012; Polishchuk et al., 2015].

- Disadvantages. Some aspects of the bridge behaviour are not known, and consequently, engineers need to address uncertainties by assuming values of some bridge parameters [Rocha et al., 2012]. The FE model updating is a very time-consuming process, therefore, a continuous SHM can be endangered by the adoption of an FE model for updating condition monitoring and fault detection strategy. The FE model updating has shown to allow only the detection of a failure in terms of existence and location.

- Artificial Neural Networks. [Shu et al., 2013] studied a short-span railway bridge in Sweden by developing a BPNN in order to detect a set of simulated failures in different locations on the bridge, under different load and speed of the train. Displacements and acceleration of the bridge were analysed. Results showed that the BPPN, which was developed in order to detect the single failure scenarios, was not working properly with the multiple failure scenarios. Furthermore, the noise of the measurement and the location of the failure can lead to a reduction of the performance of the ANN. In a similar way, [Cremona et al., 2012] analysed a short-span railway bridge in France that was strengthened in order to reduce the risk of resonance of the bridge. The acceleration and the modal characteristics of bridge before, during and after the works were used as the training set of the ANN. Finally, when new unknown future measurements of the bridge behaviour were available, the ANN was able to identify the health state of the bridge correctly.

- Advantages. The ANN is able to monitor the health state of the bridge by evaluating the measured bridge behaviour. It is possible to accurately assess and predict the health state of the bridge, if the model has been trained accurately with a vast and reliable database of bridge behaviours. Finally, it should be noted that ANN methods can be suitable for continuous and real-time monitoring of the bridge due to their ability to assess and predict the health state of the bridge when a new evidence of the bridge behaviour is available.

- Disadvantages. The performance of ANN methods strongly depends on the quality of the data that are used during the training process. It is thus important to use a vast and reliable training set, where the behaviours of the bridge are 
considered under different environmental conditions, such as different air temperature, wind conditions, train velocity and load. The definition of the network structure, particularly, the choice of the number of hidden layer and hidden nodes, is selected usually by the means of a trial and error procedure. However, the structure of the network can be optimal only for that particular case study, and consequently the developed NN does not work well for other case studies. Finally, the influences among the health state of different elements of the bridge cannot be considered.

- Unsupervised clustering techniques. [Cury et al., 2012] analysed a short-span steel railway bridge in France by developing and comparing two unsupervised clustering techniques. A database of bridge acceleration and modal properties (such as natural frequencies and mode shapes) before, during and after a strengthening process was available. Results showed that the method was able to classify new and unknown behaviour of the bridge by grouping unexpected behaviours of the bridge into a new cluster.

- Advantages. The health state of the bridge is assessed by relying only on the statistical characteristics of the measured behaviour without developing an FE model or applying the ANN method. Hence, the unsupervised clustering methods are very attractive as a tool for real-time continuous monitoring of the railway bridge, as they can rapidly assess new and unknown behaviour of the bridge, by activating an alarm if an unexpected behaviour is pointed out.

- Disadvantages. The judgement of an expert is needed, in order to evaluate the physical meaning of the clusters and to accurately assess the health state of the bridge. False alarms can be activated due to changes of the bridge behaviours that are caused by changes of environmental conditions. The future health state of the bridge and the influences among different degrading bridge elements cannot be assessed by these methods.

- Bayesian Belief Network. [Wang et al., 2012] proposed a DBN to predict the condition of the elements on a span of a steel railway bridge in Australia. The CPTs were defined by relying on expert judgments. The proposed method aimed to predict the health state of the bridge elements by using environmental effects, degradation of bridge materials and maintenance strategies as inputs of the DBN. The method showed promising results in the prediction of the bridge health state in the future.

- Advantages. BBN-based methods can assess the health state of the bridge under current and future environmental conditions, by developing a DBN. A BBN fault detection method can predict the health state of the bridge in the future, and assess how the failure of a bridge element influences the health state of other bridge elements, and consequently the health state of the whole bridge.

- Disadvantages. The performance of a BBN strongly depends on the definition of the CPTs, which can be defined using a simulation model of the bridge under investigation, or relying on expert judgement. The size of the CPTs increases as the number of nodes in the BBN increases. The probabilities of the health states of the bridge elements can be modified only slightly when an unexpected 
behaviour of the bridge is measured, and consequently, the assessment of the failure existence, location and magnitude can be difficult.

\subsection{Discussion on the comparative study}

In this section, a discussion of the presented methods on a short-span railway bridge is given by aiming to illustrate how the different SHM methods can be applied for monitoring the health state of the bridge.

The FE model updating strategy, which can be applied at every stage of the life cycle of the bridge, showed the ability to modify the parameters of the FE model in order to predict the behaviour of the real bridge with good accuracy. Therefore, if the FE model is embedded in a framework where the degradation of the materials and the future environmental scenarios are modelled and predicted by using mathematical models, the FE model can predict the expected future behaviour of the bridge. However, the FE modelling and updating is time-consuming and can put at risk the achievement of a real-time condition monitoring method of the bridge. Machine learning methods, such as ANN, demonstrated good results in classifying and identifying the health state of the bridge. However, a vast database of bridge behaviour under different environmental condition is requested in order to train the ANN in the optimal way. Moreover, usually the ANN structure is optimized by a trial and error procedure, which results in the best structure for a particular training set. On one hand, the ANN can identify the health state of the bridge effectively, by identifying possible failure and its location, but, on the other hand, the influence of the health state between different bridge elements cannot be evaluated. Unsupervised clustering methods have shown the ability to identify changes on the bridge behaviour correctly and rapidly. Indeed, unknown and unexpected behaviours of the bridge have been grouped into new clusters that point out the differences between the new behaviour of the bridge and the behaviours that have been previously observed. However, the new clusters are required to be analysed by an expert in order to assess the health state of the bridge. Furthermore, only the first three levels of the fault detection process are met by the unsupervised methods, i.e. it is not possible to predict and assess the future health state of the bridge by adopting these methods. Finally, a BBN approach demonstrated that the future condition of the bridge under different environmental conditions can be assessed. However, the performance of the BBN method strongly depends on the definition of the CPTs and the fault detection process can be threatened by the complexity of the BBN structure.

Overall, it is worth highlighting, that on one hand non-model-based methods can experience difficulties on the assessment of the health state of a short-span railway bridge, whose response is strongly influenced by external disturbances. On the other hand, model-based methods can simulate and predict the behaviour of the bridge, however, the interaction between the bridge structure, the track and the train can be difficult to model accurately. Therefore, a comprehensive method that is able to answer all four requirements of the fault detection process, i.e. which is able to detect and diagnose failure of the bridge and to assess its future health state, is not yet available. However, all the presented methods provide good results in their area of competence, e.g. the FE model is suitable for simulating the behaviour of the bridge, ANN methods - in predicting or classifying the health state of the bridge, unsupervised 
clustering methods - in grouping the behaviour of the bridge by analysing the statistical properties of the measured data, and the BBN - to assess the influence among different degrading elements of the bridge and in predicting the future health state of the bridge. Furthermore, the non-model-based methods improve their performance by providing good and reliable results when a large database of recorded bridge behaviours is available. Therefore, an SHM approach that could combine the advantages of the proposed methods can lead to a comprehensive, continuous, fast and reliable condition monitoring and fault detection process of railways bridges.

\section{Future challenges}

Currently, vibration-based methods are the most commonly developed SHM methods in literature, due to the fact that modal parameters are usually easily interpreted by an analyst [Carden et al., 2004]. The fundamental idea for vibration-based damage identification is that the damage-induced changes in the physical properties (mass, damping, and stiffness) will cause detectable changes in modal properties (natural frequencies, modal damping, and mode shapes). Therefore, it is intuitive that damage can be identified by analysing the changes in vibration features of the structure [Fan et al., 2011]. However, a comprehensive method, which is able to correctly identify failures in different type of bridge structures, has not yet been proposed, and modal parameters have been demonstrated to be sensitive to high magnitude failure scenario, and the nature of the failure cannot be usually assessed [Brownjohn et al., 2011; Webb et al., 2015]. For these reasons, the future challenges for an SHM method can be described as follows:

- Innovative condition monitoring and fault detection methods should be developed with the aim of reducing the whole life cost of bridges, by overcoming the limitations and weaknesses of the traditional bridge health assessment methods. In this way, a more accurate assessment of the health state and, therefore, better maintenance planning and asset management, can be obtained [Alves et al., 2015]. These innovative methods should be able to not only detect and diagnose faults automatically, but also to assess the residual useful life of the bridge, which would be an important output used by bridge managers, with the aim of achieving a minimal life-cycle cost of the asset by determining the type and schedule of the optimal maintenance actions to be performed on each bridge element [Fernando et al., 2013]. For example, an increasing interest by the research community is towards the use of hybrid and ensemble methods in order to develop new and accurate comprehensive SHM method:

- A hybrid method aims to assess the health state of the system merging different types of information or data, which can come from multiple sources (for example, data from both railway and train) and of different types (for example, maintenance records and measurements of the track quality) [Galar et al., 2013].

- An ensemble method aims to overcome errors of a single SHM method, which is usually optimized for specified operational conditions (e.g. a non-modelbased method cannot guarantee good performance for new and previously unknown operational conditions which have been not included in the database 
used to train the method), assessing the system health state through a combination of the evaluations of the individual SHM models. Thus, analysing the pros and cons of the model-based and non-model-based methods, an exhaustive ensemble SHM method, which can be able to overcome the errors of the singular method, can be developed [Zio, 2012].

It is worth recalling the desirable characteristics of the SHM method that have been presented in section 2: quick in detecting and diagnosing faults, able to distinguish between different failures, robust to measurement noise and data uncertainties and, finally, able to decide, given current process conditions, whether the process is functioning normally or abnormally, and if it is abnormal, whether the cause is a known or an unknown malfunction [Venkatasubramanian et al., 2003; Zio, 2012]. These desirable characteristics help to assess the fault existence, location and severity, and to determine the system residual useful life, which means that by adopting the SHM method the fault analysis evaluation can performed at all four levels [Wang et al., 2009].

- Integration of optimal continuous monitoring system. The success of an SHM method in satisfying all the above mentioned desiderata concepts strongly depends on the integration of intelligent and optimal measurement system, which provides the best quality of the measured structural response data [Ntotsios et al., 2009; Vardanega et al., 2016]. Indeed, in order to support the decision-making process in a reliable way a reduction of all types of system uncertainties is also needed [Catbas et al., 2008; Lebeau et al., 2010]. A continuous SHM is one of the most desiderata aspect of SHM due to the continuous deterioration of the bridge and its components. Indeed, the deterioration process is continuously caused by aging of the bridge, traffic load, and environmental effect [Wellalage et al., 2015]. Furthermore, a complex system such a bridge can be efficiently and reliably monitored by adopting hybrid and integrated sensor system, consisting of GPS receivers, accelerometers, strain gauges and weather stations. The information of different type of sensors can then be merged to increase the accuracy of the SHM assessment through a data fusion method, as successfully demonstrated for mechanical systems [Jardine et al., 2006].

- Remote monitoring. The measuring system should provide remote condition monitoring by transmitting data to data analysis centres. The transmission using networking technologies, such as wireless sensor network (WSN), which have been thoroughly developed in recent years, seems to give the opportunity to develop a cheaper continuous and autonomous measurement system for bridge SHM than a cablebased measurement system [Akyidiz et al., 2002]. Indeed, even if a cable-based system can transmit large amounts of data in a more reliable way than a WSN due to the fact that data transmission with WSN suffers of several limitations, such as short distance and limited-bandwidth transmission [Hu et al., 2013], time consuming and costly installation are required by this sensor strategy [Stajano et al., 2010]. WSN, which can be quickly installed, is able to perform independent activities, such as preliminary data processing of the acquired data, self-monitoring of supply energy and communication link, scheduling of the measurements, etc. [Flouri et al., 2012]. However, the WSN nodes are battery powered, and thus the power management is vital to maximize their durability. 
- Embedding future environmental conditions on SHM. Bridges are critical transportation infrastructures that are designed to safely operate for long periods of time. It is thus important to assess and predict how changes of the environmental conditions (such as climate, traffic load and degradation mechanisms) influence the safety of the bridge [He et al., 2008; Xie et al., 2011]. For example, the future traffic load depends on the demand of passengers and goods which is expected to increase in the future due to the growth in technology and economy [Zio, 2016]. Climate change is a severe issue, as it has been demonstrated that changes of air temperature and humidity lead to bridge responses that can be confused with a failure [Xia et al., 2006]. Consequently, as the Arctic Climate Impact Assessment and the Intergovernmental Panel on Climate Change claim that the actual global climate change is expected to continue and grow in the future, the capability of critical infrastructure, such as transportation network, to withstand the changes in climate in the forthcoming years is of a major concern [Khelifa et al., 2013; Ikpong et al., 2015; Sahlin et al., 2015]. It is thus therefore desirable to analyse how climate change can be taken into account by SHM of bridges. In order to understand the importance of climate, it is worth noting that, more than 3,000 hours of delays have been experienced during two particularly hot summers in 2003 and 2004 in the UK railway network [Hooper et al., 2012; Santillán et al., 2015].

For these reasons, in order to improve the management of the bridge, by using a conditionbased maintenance strategy (which allows to promptly carry out required maintenance works on the transportation network based on the condition of the bridge, in order to keep the bridge in safe and good condition), and to improve the reliability of the whole railway network, the continuous monitoring of the health state of the bridge by considering the bridge as a whole system (i.e. analysing the influence among the degradation mechanism of different bridge element), and the prediction of future health state of the bridge and its components under future unknown environmental conditions, is of great importance.

\section{Conclusion}

The continuous growth of demand on railway networks instigates an efficient asset management strategy. Indeed, in order to improve safety and availability of the railway network and to achieve an optimal management of the budget, innovative SHM methods that are able to continuously monitor the railway network are required. Particularly, it has been demonstrated in literature that bridges are a vital element of the railway infrastructure and, thus, their SHM is a key challenge in providing rapid and reliable information to the railway administrators, in order to schedule current and future maintenance plans by adopting a condition-based maintenance strategy. With this aim, desiderata concepts for the development of an optimal SHM method have been proposed in this paper, by highlighting the need of a rapid, robust and automatic detection of faults of the bridge elements, where the behaviour of the bridge should be monitored efficiently in real-time by a measurement system that is optimized in terms of sensor type, location and cost. It is worth noting that an intelligent and 
optimal measurement system, that allows remote condition monitoring of the bridge, is a milestone in the development of an efficient SHM strategy of the asset.

A review of the most commonly adopted SHM methods has been discussed by underling the pros and cons of model-based and non-model-based for SHM: the model-based FE model updating strategies can simulate the behaviour of the bridge by considering different expected degradation mechanisms, however, a time-consuming process is required to develop the $\mathrm{FE}$ model accurately. Consequently, such methods are not suitable for continuous SHM. On the other hand, non-model-based methods have shown good results in some case studies, but their accuracy has been proven to rely on the data used in the training process of the method. Finally, although the potential of the BBN methods for real-time SHM has been highlighted, in literature these methods have been mainly developed for reliability analysis rather than fault detection process.

A comparative study on a short-span steel structure of a railway bridge has been presented by illustrating the advantages and the limitations of the main groups of the SHM methods. It has been discussed that these methods have clear advantages in certain steps of the fault detection process, but an SHM method that is able to satisfy all the four requirements of the process is still needed. Hence, in order to reduce the whole life cost of bridges by overcoming the limitations and weaknesses of the traditional bridge health assessment methods, future challenges lie in proposing comprehensive SHM methods that are able to monitor the bridge behaviour continuously, to detect and diagnose faults of its elements and predict its future health state. For example, hybrid and ensemble SHM methods, which are also able to use data from different sources, can be developed in order to improve the performance of each method by overcoming the limitation of each single method. Finally, the changes of the environmental condition, such as traffic load and climate change scenarios, have to be incorporated into the SHM analysis, with the aim to predict the health state of the railway bridge under unknown future environmental conditions.

\section{Funding}

This project has received funding from the European Union's Horizon 2020 research and innovation programme under the Marie Skłodowska-Curie grant agreement No. 642453. 


\section{References}

[Adey et al., 2004] Adey, B., Hajdin, R., Brühwiler, E., "Effect of common cause failures on indirect costs", Journal of Bridge Engineering, 9 (2), pp. 200-208, 2004.

[AISI, 2007] American Iron and Steel Institute, "Steel Bridge Construction: Myths \& Realities", D432-07 booklet, 2007.

[Akyidiz et al., 2002] Akyidiz, I. F., Su, W., Sankarasubramaniam, Y., Cayirci, E., "Wireless sensor network: a survey", Computer Networks, 38(4), pp. 393-422, 2002.

[Al-Rahmani et al., 2012] Al-Rahmani, A.H., Rasheed, H.A., Najjar, Y., "A combined soft computing-mechanics approach to inversely predict damage in bridges", Procedia Computer Science, 8, pp. 461-466, 2012.

[Alves et al., 2015] Alves, V., Meixedo, A., Ribeiro, D., Calçada, R., Cury, A., "Evaluation of the Performance of Different Damage Indicators in Railway Bridges", Procedia Engineering, 114, pp. 746-753, 2015.

[Alves et al., 2015b] Alves, V., Cury, A., Roitman, N., Magluta, C., Cremona, C., "Novelty detection for SHM using raw acceleration measurements", Structural Control and Health Monitoring, 22 (9), pp. 1193-1207, 2015.

[Alves et al., 2015c] Alves, V., Cury, A., Roitman, N., Magluta, C., Cremona, C., "Structural modification assessment using supervised learning methods applied to vibration data", Engineering Structures, 99, pp. 439-448, 2015.

[Alves et al., 2016] Alves, V., Cury, A., Cremona, C., "On the use of symbolic vibration data for robust structural health monitoring", Proceedings of the Institution of Civil Engineers: Structures and Buildings, 169 (9), pp. 715-723, 2016.

[Andersen et al., 2006] Andersen, J.E. and Fustinoni, M., "Structural Health Monitoring Systems", L\&S S.r.l. Servizi Grafici, 2006.

[Arangio et al., 2014] Arangio, S., Bontempi, F., "Structural health monitoring of a cablestayed bridge with Bayesian neural networks", Structure and Infrastructure Engineering, Article in Press, 2014.

[Araújo and Laier, 2014] Araújo, I.G., Laier, J.E., "Operational modal analysis using SVD of power spectral density transmissibility matrices", Mechanical Systems and Signal Processing, 46 (1), pp. 129-145, 2014.

[Attema et al., 2017] Attema, T., Kosgodagan Acharige, A., Morales-Nápoles, O., Maljaars, J., "Maintenance decision model for steel bridges: a case in the Netherlands", Structure and Infrastructure Engineering, 13 (2), pp. 242-253, 2017.

[Attoh-Okine \& Bowers, 2006] Attoh-Okine, N.O., Bowers, S., "A Bayesian belief network model of bridge deterioration", Proceedings of the Institution of Civil Engineers: Bridge Engineering, 159 (2), pp. 69-76, 2006.

[Azarbayejani et al., 2008] Azarbayejani, M., El-Osery, A.I., Choi, K.K., Reda Taha, M.M., "A probabilistic approach for optimal sensor allocation in structural health monitoring", Smart Materials and Structures, 17 (5), art. no. 055019, 2008.

[Baraldi et al., 2015] Baraldi, P., Di Maio, F., Rigamonti, M., Zio, E., Seraoui, R., "Clustering for unsupervised fault diagnosis in nuclear turbine shut-down transients", Mechanical Systems and Signal Processing, 58, pp. 160-178, 2015.

[Barnes et al., 2005] Barnes, J., Rizos, C., Kanli, M., Pahwa, A., Small, D., Voigt, G., Gambale, N., Lamance, J., "High accuracy positioning using Locata's next generation technology", Proceedings of the 18th International Technical Meeting of the Satellite Division of The Institute of Navigation, , pp. 2049-2056, 2005.

[Başaĝa et al., 2011] Başaĝa, H.B., Türker, T., Bayraktar, A., "A model updating approach based on design points for unknown structural parameters", Applied Mathematical Modelling, 35 (12), pp. 5872-5883, 2011. 
[Basheer \& Hajmeer, 2000] Basheer, I.A., Hajmeer, M., "Artificial neural networks: Fundamentals, computing, design, and application", Journal of Microbiological Methods, 43 (1), pp. 3-31, 2000.

[Bellino et al., 2010] Bellino, A., Fasana, A., Garibaldi, L., Marchesiello, S., "PCA-based detection of damage in time-varying systems", Mechanical Systems and Signal Processing, 24 (7), pp. 2250-2260, 2010.

[Berger et al., 2004] Berger, J.O., Bayarri, M.J., "The Interplay of Bayesian and Frequentist Analysis", Statistical Science, 19, pp. 58-80, 2004.

[Bishop, 1995] Bishop, C. M., "Neural Networks for pattern recognition", Clarendon press - Oxford, book, 1995.

[Brereton, 2015] Brereton, R.G., "The mahalanobis distance and its relationship to principal component scores", Journal of Chemometrics, 29 (3), pp. 143-145, 2015.

[Brown et al., 1999] Brown, C. J., Karuna, R., Ashkenazi, V., Roberts, G. W., and Evans, R. A., "Monitoring of structures using the Global Positioning System', Proc. Institution of Civil Engineers Structures and Buildings, pp. 97-105, 1999.

[Brownjohn et al., 2001] Brownjohn, J.M.W., Xia, P.Q., Hao, H., Xia, Y. "Civil structure condition assessment by FE model updating: methodology and case studies", Finite Elements in Analysis and Design, 37, pp. 761-775, 2001.

[Brownjohn et al., 2011] Brownjohn, J. M. W., De Stafano, A., Xu, Y.-L., Wenzel, H., and Aktan, A. E., "Vibration-based monitoring of civil infrastructure: Challenges and successes", Journal of Civil Structures Health Monitoring, 1(3-4), 79-95, 2011.

[Cabboi et al., 2014] Cabboi, A., Gentile, C., Saisi, A., "Vibration-based SHM of a centenary bridge: A comparative study between two different automated OMA techniques", Proceedings of the International Conference on Structural Dynamic , EURODYN, 2014January, pp. 1461-1468, 2014.

[Cao et al., 2011] Cao, Y., Yim, J., Zhao, Y., Wang, M.L., "Temperature effects on cable stayed bridge using health monitoring system: A case study", Structural Health Monitoring, 10 (5), pp. 523-537, 2011.

[Carden et al., 2004] Carden, E.P., Fanning, P., "Vibration based condition monitoring: A review", Structural Health Monitoring, 3 (4), pp. 355-377, 2004.

[Catbas et al., 2008] Catbas, F.N., Susoy, M., Frangopol, D.M., "Structural health monitoring and reliability estimation: Long span truss bridge application with environmental monitoring data", Engineering Structures, 30 (9), pp. 2347-2359, 2008. [Cavadas et al., 2013] Cavadas, F., Smith, I.F.C., Figueiras, J., "Damage detection using data-driven methods applied to moving-load responses", Mechanical Systems and Signal Processing, 39 (1-2), pp. 409-425, 2013.

[CDT, 2012] Connecticut department of transportation - Office of Rail, H.W. Lochner, Inc., "Railroad bridge inspection manual", Connecticut department of transportation Bureau of Public Transportation - Office of Rail, 2012.

[Chan et al., 2001] Chan, T., Li, X., Ko, J., "Fatigue analysis and life prediction of bridges with structural health monitoring data - Part II: application", International Journal of Fatigue, 23, pp. 55-64, 2001.

[Chang et al., 2000] Chang, C.C., Chang, T.Y.P., Xu, Y.G., "Adaptive neural networks for model updating of structures", Smart Materials and Structures, 9 (1), pp. 59-68, 2000.

[Chang et al., 2014] Chang, K.-C., Kim, C.-W., Kawatani, M., "Feasibility investigation for a bridge damage identification method through moving vehicle laboratory experiment", Structure and Infrastructure Engineering, 10 (3), pp. 328-345, 2014.

[Chase et al., 2001] Chase, S.B., Aktan, A.E., "Health Monitoring and Management of Civil Infrastructure Systems”, SPIE, Vol. 4337, Bellingham, WA, 2001. 
[Chase, 2004] Chase, S.B., "A long term bridge performance monitoring program", Proceedings of SPIE - The International Society for Optical Engineering, 5395, pp. 122127, 2004.

[Chattopadhyay et al., 2007] G. Chattopadhyay, V. Reddy, "Development of integrated model for assessment of operational risks in rail track", IEEE International Conference on Industrial Engineering and Engineering Management, 612 - 616, 2007.

[Chen \& Pollino, 2012] Chen, S.H., Pollino, C.A., "Good practice in Bayesian network modelling", Environmental Modelling and Software, 37, pp. 134-145, 2012.

[Chen et al., 1999] Chen, W.F., Duan, L., "Bridge Engineering Handbook", CRC press, ISBN 0849374340, 1999.

[Coolen, 1992] Coolen, F.P.A., "A Bayes-competing risk model for the use of expert judgment in reliability estimation", Reliability Engineering, 14, pp.1079-30, 1992.

[Coolen, 1996] Coolen, F.P.A., "On Bayesian reliability analysis with informative priors and censoring”, Reliability Engineering and System Safety, 53, pp. 91-98, 1996.

[Corbetta et al., 2015] Corbetta, M., Sbarufatti, C., Manes, A., Giglio, M., "Real-time prognosis of crack growth evolution using sequential Monte Carlo methods and statistical model parameters", IEEE Transactions on Reliability, 64 (2), art. no. 6953312, pp. 736753, 2015.

[Cremona et al., 2012] Cremona, C., Cury, A., Orcesi, A., "Supervised learning algorithms for damage detection and long term bridge monitoring", Bridge Maintenance, Safety, Management, Resilience and sustainability - Proceedings of the Sixth International Conference on Bridge Maintenance, Safety and Management, pp. 2144-2151, 2012. [Cury et al., 2012] Cury, A., Crémona, C., "Assignment of structural behaviours in longterm monitoring: Application to a strengthened railway bridge", Structural Health Monitoring, 11 (4), pp. 422-441, 2012.

[Deb et al., 2002] K. Deb, A. Pratap, S. Agarwal, and T. Meyarivan, "A fast and elitist multiobjective genetic algorithm: NSGA-II," IEEE Transactions on Evolutionary Computation, vol. 6, no. 2, pp. 182-197, 2002.

[Demuth et al., 2014] Demuth, H.B., Beale, M.H., De Jess, O., Hagan, M.T., "Neural network design", Martin Hagan, 2014.

[Di Maio et al., 2015] Di Maio, F., Vagnoli, M., Zio, E., "Risk-based clustering for near misses identification in integrated deterministic and probabilistic safety analysis", Science and Technology of Nuclear Installations, art. no. 693891, 2015.

[Ding \& Li, 2008] Ding, Y., Li, A., "Finite element model updating for the Runyang Cable-stayed Bridge tower using ambient vibration test results", Advances in Structural Engineering, 11 (3), pp. 323-335, 2008.

[Ding et al., 2015] Ding, Y.-L., Wang, G.-X., Sun, P., Wu, L.-Y., Yue, Q., "Long-Term Structural Health Monitoring System for a High-Speed Railway Bridge Structure", Scientific World Journal, 2015, art. no. 250562, 2015.

[Doebling et al., 1996] Doebling, S. W., Farrar, C. R., Prime, M. B. and Shevitz, D. W., "Damage Identification and Health Monitoring of Structural and Mechanical Systems from Changes in their Vibration Characteristics: A Literature Review", Los Alamos National Laboratory report, LA-13070-MS, 1996.

[Doebling et al., 1998] Doebling, S.W., Farrar, C.R., Prime, M.B., "A summary review of vibration-based fault identification methods, the shock and vibration", Digest, 30 (2), pp. 91-105, 1998.

[Duhamel \& Vetterli, 1990] Duhamel, P., Vetterli, M., "Fast fourier transforms: A tutorial review and a state of the art", Signal Processing, 19 (4), pp. 259-299, 1990.

[Elfgren et al., 2008] Elfgren, L., Olofsson, J., Bell, B., Paulsson, B., Niederleithinger, E., Jensen, J.S., Feltrin, G., Täljsten, B., Cremona, C., Kiviluoma, R., Bien, J., "Sustainable 
Bridges - Assessment for Future Traffic Demands and Longer Lives", Priority sixth sustainable development global change \& ecosystems integrated project, Publishable Final Activity Report, Sustainable Bridges, 2008.

[European Commission, 2012] European Commission, "EU transport in figures", statistical pocketbook, 2012.

[Fan et al., 2011] Fan, W., Qiao, P., "Vibration-based damage identification methods: A review and comparative study", Structural Health Monitoring, 10 (1), pp. 83-111, 2011. [Feng et al., 2015] Feng, D., Feng, M.Q., "Model Updating of Railway Bridge Using in Situ Dynamic Displacement Measurement under Trainloads", Journal of Bridge Engineering, 20 (12), art. no. 04015019, 2015.

[Fernando et al., 2013] Fernando, D., Adey, B.T., Walbridge, S., "A methodology for the prediction of structure level costs based on element condition states", Structure and Infrastructure Engineering, 9 (8), pp. 735-748, 2013

[Flouri et al., 2012] Flouri, K., Saukh, O., Sauter, R., Jalsan, K.E., Bischoff, R., Meyer, J., Feltrin, G., "A versatile software architecture for civil structure monitoring with wireless sensor networks", Smart Structures and Systems, 10 (3), pp. 209-228, 2012.

[Franchin et al., 2016] Franchin, P., Lupoi, A., Noto, F., Tesfamariam, S., "Seismic fragility of reinforced concrete girder bridges using Bayesian belief network", Earthquake Engineering and Structural Dynamics, 45 (1), pp. 29-44, 2016.

[Galar et al., 2013] Galar, D., Kumar, U., Villarejo, R., Johansson, C.-A., "Hybrid prognosis for railway health assessment: An information fusion approach for PHM deployment", Chemical Engineering Transactions, 33, pp. 769-774, 2013.

[Galotto et al., 2015] Galotto, L., Brun, A.D.M., Godoy, R.B., Maciel, F.R.R., Pinto, J.O.P., "Data based tools for sensors continuous monitoring in industry applications", IEEE International Symposium on Industrial Electronics, 2015-September, art. no. 7281536, pp. 600-605, 2015.

[Gangone et al., 2011] Gangone, M.V., Whelan, M.J., Janoyan, K.D., "Wireless monitoring of a multispan bridge superstructure for diagnostic load testing and system identification", Computer-Aided Civil and Infrastructure Engineering, 26 (7), pp. 560-579, 2011.

[Gelman et al., 1996] Gelman, A., Bois, F., Jiang, J., "Physiological pharmacokinetic analysis using population modeling and informative prior distributions", Journal of the American Statistical Association, 91, pp. 1400-1412, 1996.

[Gentile et al., 2015] Gentile, C., Saisi, A., "Continuous dynamic monitoring of a centenary iron bridge for structural modification assessment", Frontiers of Structural and Civil Engineering, 9 (1), pp. 26-41, 2015.

[Goodall et al., 2006] Goodall, R.M., Roberts, C., "Concepts and techniques for railway condition monitoring”, IET Seminar Digest, 2006 (11575), pp. 90-95, 2006.

[Gu et al., 2010] Gu, Y., Wang, J., Han, R., "Dynamic Bayesian network optimized by particle filtering in gene regulatory networks", International Conference on E-Health Networking, Digital Ecosystems and Technologies, art. no. 5496445, pp. 512-515, 2010. [Guikema, 2007] Guikema, S.D., "Formulating informative, data-based priors for failure probability estimation in reliability analysis", Reliability Engineering and System Safety, 92, pp.490-502, 2007.

[Guo et al., 2012] Guo, W., Orcesi, A.D., Cremona, C.F., Santos, J.P., Yang, S., Dieleman, L., "A vibration-based framework for structural health monitoring of railway bridges", Life-Cycle and Sustainability of Civil Infrastructure Systems - Proceedings of the 3rd International Symposium on Life-Cycle Civil Engineering, IALCCE 2012, pp. 1118-1125, 2012. 
[Hakim et al., 2013] Hakim, S.J.S., Abdul Razak, H., "Structural damage detection of steel bridge girder using artificial neural networks and finite element models", Steel and Composite Structures, 14 (4), pp. 367-377, 2013.

[Han et al., 2015] Han, H., Wang, J., Meng, X., "Reconstruction of bridge dynamics using integrated GPS and accelerometer", Journal of China University of Mining and Technology, 44 (3), pp. 549-556, 2015.

[He et al., 2008] He, X.-H., Yu, Z.-W., Chen, Z.-Q., "Finite element model updating of existing steel bridge based on structural health monitoring", Journal of Central South University of Technology (English Edition), 15 (3), pp. 399-403, 2008.

[He et al., 2011] He, X., Kawatani, M., Hayashikawa, T., Furuta, H., Matsumoto, T., " $A$ bridge damage detection approach using train-bridge interaction analysis and GA optimization", Procedia Engineering, 14, pp. 769-776, 2011.

[Hodge et al., 2015] Hodge, V.J., O'Keefe, S., Weeks, M., Moulds, A., “Wireless sensor networks for condition monitoring in the railway industry: A survey", IEEE Transactions on Intelligent Transportation Systems, 16 (3), art. no. 6963375, pp. 1088-1106, 2015.

[Hoell et al., 2017] Hoell, S. and Omenzetter, P., "Fukunaga-Koontz feature transformation for statistical structural damage detection and hierarchical neuro-fuzzy damage localisation", Journal of Sound and Vibration, 400, pp.329-353, 2017.

[Holický et al., 2013] Holický, M., Marková, J., Sýkora, M., "Forensic assessment of a bridge downfall using Bayesian networks", Engineering Failure Analysis, 30, pp. 1-9, 2013.

[Hooper et al., 2012] Hooper, E., Chapman, L., "The impacts of climate change on national road and rail networks", Transport and Sustainability, 2, pp. 105-136, 2012.

[Hoult et al., 2010] N. Hoult, P. Fidler, P. Hill, C. Middleton, "Wireless structural health monitoring of bridges: present and future", Smart Structures and Systems, 6 (3), pp. $277-$ 290, 2010.

[Hu et al., 2013] Hu, X., Wang, B., Ji, H., “A Wireless Sensor Network-Based Structural Health Monitoring System for Highway Bridges" Computer-Aided Civil and Infrastructure Engineering, 28 (3), pp. 193-209, 2013.

[Ignat-Coman et al., 2008] Ignat-Coman, A., Isoc, D., Joldiş, A., Gaziuc, I., "A case-based reasoning approach for fault detection state in bridges assessment", IEEE International Conference on Automation, Quality and Testing, Robotics, art. no. 4588730, pp. 178-183, 2008.

[Ikpong et al., 2015] Ikpong, A., Bagchi, A., "New method for climate change resilience rating of highway bridges", Journal of Cold Regions Engineering, 29 (3), art. no. 04014013, 2015.

[Jaishi \& Ren, 2005] Jaishi, B., Ren, W.-X., "Structural finite element model updating using ambient vibration test results", Journal of Structural Engineering, 131 (4), pp. 617 $628,2005$.

[Jardine et al., 2006] Jardine, A.K.S., Lin, D., Banjevic, D., "A review on machinery diagnostics and prognostics implementing condition-based maintenance”, Mechanical Systems and Signal Processing, 20 (7), pp. 1483-1510, 2006.

[Jensen \& Nielsen, 2007] Jensen, F.V., Nielsen, T. D., "Bayesian Networks and Decision Graphs", Information Science and Statistics, Springer, 2007.

[Jin et al., 2014] Jin, S.-S., Cho, S., Jung, H.-J., Lee, J.-J., Yun, C.-B., “A new multiobjective approach to finite element model updating", Journal of Sound and Vibration, 333 (11), pp. 2323-2338, 2014.

[Kallias et al., 2016] Kallias, A.N., Imam, B., "Probabilistic assessment of local scour in bridge piers under changing environmental conditions", Structure and Infrastructure Engineering, 12 (9), pp. 1228-1241, 2016. 
[Kan et al., 2015] Kan, M.S., Tan, A.C.C., Mathew, J., "A review on prognostic techniques for non-stationary and non-linear rotating systems", Mechanical Systems and Signal Processing, 62, pp. 1-20, 2015.

[Katipamula et al., 2005] Katipamula, S., Brambley, M.R., "Methods for fault detection, diagnostics, and prognostics for building systems - A review, Part I', HVAC and R Research, 11 (1), pp. 3-25, 2005.

[Khelifa et al., 2013] Khelifa, A., Garrow, L.A., Higgins, M.J., Meyer, M.D., "Impacts of climate change on scour-vulnerable bridges: Assessment based on HYRISK", Journal of Infrastructure Systems, 19 (2), pp. 138-146, 2013.

[Kim et al., 2007] Kim, J.-T., Park, J.-H., Lee, B.-J., "Vibration-based damage monitoring in model plate-girder bridges under uncertain temperature conditions", Engineering Structures, 29 (7), pp. 1354-1365, 2007.

[Kim et al., 2015] Kim, C.-W., Morita, T., Oshima, Y., Sugiura, K., “A Bayesian approach for vibration-based long-term bridge monitoring to consider environmental and operational changes", Smart Structures and Systems, 15 (2), pp. 395-408, 2015.

[Kreislova et al., 2012] Kreislova, K., Geiplova, H., "Evaluation of corrosion protection of steel bridges", Procedia Engineering, 40, pp. 229-234, 2012.

[Krüger et al., 2006] Krüger, M., Grosse, C.U., Kurz, J.H., "Acoustic emission analysis techniques for wireless sensor networks used for structural health monitoring",

Proceedings of the 3rd International Conference on Bridge Maintenance, Safety and Management - Bridge Maintenance, Safety, Management, Life-Cycle Performance and Cost, pp. 873-874, 2006.

[Kusy \& Zajdel, 2014] Kusy, M., Zajdel, R., "Probabilistic neural network training procedure based on Q(0)-learning algorithm in medical data classification", Applied Intelligence, 41 (3), pp. 837-854, 2014.

[Lampis et al., 2009] Lampis, M., Andrews, J.D., “Bayesian belief networks for system fault diagnostics", Quality and Reliability Engineering International, 25 (4), pp. 409-426, 2009.

[Langone et al., 2017] Langone, R., Reynders, E., Mehrkanoon, S., Suykens, J.A.K., "Automated structural health monitoring based on adaptive kernel spectral clustering", Mechanical Systems and Signal Processing, 90, pp. 64-78, 2017.

[Laory et al., 2012] Laory, I., Hadj Ali, N.B., Trinh, T.N., Smith, I.F.C., "Measurement system configuration for damage identification of continuously monitored structures", Journal of Bridge Engineering, 17 (6), pp. 857-866, 2012.

[Laory et al., 2013] Laory, I., Trinh, T.N., Posenato, D., Smith, I.F.C., "Combined modelfree data-interpretation methodologies for damage detection during continuous monitoring of structures", Journal of Computing in Civil Engineering, 27 (6), pp. 657-666, 2013.

[Le et al., 2013] Le B., Andrews J., "Modelling railway bridge asset management", Proceedings of the Institution of Mechanical Engineers, Part F: Journal of Rail and Rapid Transit, 227 (6), pp. 644-656, 2013.

[LeBeau et al., 2000] LeBeau, K., Wadia-Fascetti, S., "A fault tree model of bridge deterioration", 8th ASCE conference on probabilistic mechanics and structural reliability, Indiana, USA, 2000.

[Lebeau et al., 2010] Lebeau, K., Wadia-Fascetti, S., "Predictive and diagnostic load rating model of a prestressed concrete bridge", Journal of Bridge Engineering, 15 (4), pp. 399-407, 2010.

[Lédeczi et al., 2009] Lédeczi, Á., Hay, T., Völgyesi, P., Hay, D.R., Nádas, A., Jayaraman, S., "Wireless acoustic emission sensor network for structural monitoring", IEEE Sensors Journal, 9 (11), art. no. 5257356, pp. 1370-1377, 2009. 
[Lee \& Yun, 2007] Lee, J.J., Yun, C.B., "Damage localization for bridges using probabilistic neural networks", Structural Engineering, KSCE Journal of Civil Engineering, 11 (2), pp. 111-120, 2007.

[Lee et al., 2002] Lee, J.W., Kim, J.D., Yun, C.B., Yi, J.H., Shim, J.M., "Healthmonitoring method for bridges under ordinary traffic loadings", Journal of Sound and Vibration, 257 (2), pp. 247-264, 2002.

[Lee et al., 2005] Lee, J.J., Lee, J.W., Yi, J.H., Yun, C.B., Jung, H.Y., "Neural networksbased fault detection for bridges considering errors in baseline finite element models", Journal of Sound and Vibration, 280 (3-5), pp. 555-578, 2005.

[Lee et al., 2007] J. Lee, S. Kim, "Structural Damage Detection in the Frequency Domain using Neural Networks", Journal of Intelligent Material Systems and Structures, 18(8), 785-792, 2007.

[Lee et al., 2014] Lee, J., Wu, F., Zhao, W., Ghaffari, M., Liao, L., Siegel, D., "Prognostics and health management design for rotary machinery systems - Reviews, methodology and applications", Mechanical Systems and Signal Processing, 42 (1-2), pp. 314-334, 2014. [Li et al., 2004] Li, Z.N., Tang, J., Li, Q.S., "Optimal sensor locations for structural vibration measurements", Applied Acoustics, 65 (8), pp. 807-818, 2004.

[Li et al., 2011] Li, J., Dackermann, U., Xu, Y.-L., Samali, B., "Damage identification in civil engineering structures utilizing PCA-compressed residual frequency response functions and neural network ensembles", Structural Control and Health Monitoring, 18 (2), pp. 207-226, 2011.

[Liu et al., 2008] Liu, W., Gao, W.-c., Sun, Y., Xu, M.-j., “Optimal sensor placement for spatial lattice structure based on genetic algorithms", Journal of Sound and Vibration, 317 (1-2), pp. 175-189, 2008.

[Lynch et al., 2006] Lynch, J. P., Loh, K. J., “A summary review of wireless sensors and sensor networks for structural health monitoring”, Shock and Vibration Digest, 38(2), pp. 91-128, 2006.

[Martins et al., 2007] Martins, J.F., Pires, V.F., Pires, A.J., “Unsupervised neural-networkbased algorithm for an on-line diagnosis of three-phase induction motor stator fault", IEEE Transactions on Industrial Electronics, 54 (1), pp. 259-264, 2007.

[Mast et al., 1999] Mast, T.A., Reed, A.T., Yukovich, S., Ashby, M., Adibhatla, S., "Bayesian belief networks for fault identification in aircraft gas turbine engines", Proceedings of the 1999 IEEE International Conference on Control Applications, Kohala Coast, HI, U.S.A., vol. 1, pp. 39-44, 1999.

[Mehrjoo et al., 2008] Mehrjoo, M., Khaji, N., Moharrami, H., Bahreininejad, A., "Damage detection of truss bridge joints using Artificial Neural Networks", Expert Systems with Applications, 35 (3), pp. 1122-1131, 2008.

[Meo \& Zumpano, 2005] Meo, M., Zumpano, G., "On the optimal sensor placement techniques for a bridge structure", Engineering Structures, 27 (10), pp. 1488-1497, 2005.

[Moliner et al., 2014] Moliner, E., Cuadrado, M., "Assessment of long-term structural health at Villanueva del Jalón Viaduct”, Civil-Comp Proceedings, 104, 2014.

[Moschas et al., 2011] Moschas, F., Stiros, S., "Measurement of the dynamic displacements and of the modal frequencies of a short-span pedestrian bridge using GPS and an accelerometer", Engineering Structures, 33 (1), pp. 10-17, 2011.

[Mottershead \& Friswell, 1993] Mottershead, J.E. and Friswell, M.I., "Model updating in structural dynamics: a survey", Journal of Sound and Vibration, 167(2), 347-375, 1993. [Nair et al., 2010] Nair, A., Cai, C.S., "Acoustic emission monitoring of bridges: Review and case studies", Engineering Structures, 32 (6), pp. 1704-1714, 2010.

[Network Rail, 2004] Network Rail, "Structures condition marking index handbook for bridges", NR/GN/CIV/04, Issue 3, Network Rail, UK, 2004. 
[Neumann et al., 2015] Neumann, J.E., Price, J., Chinowsky, P., Wright, L., Ludwig, L., Streeter, R., Jones, R., Smith, J.B., Perkins, W., Jantarasami, L., Martinich, J., “Climate change risks to US infrastructure: impacts on roads, bridges, coastal development, and urban drainage", Climatic Change, 131 (1), pp. 97-109, 2015.

[Ni, 2014] Ni, Y. Q., "Structural health monitoring of cable-supported bridges based on vibration measurements", Proceedings of the 9th International Conference on Structural Dynamics, EURODYN 2014 Porto, Portugal, 2014.

[Nielsen et al., 2013] Nielsen, D., Raman, D., Chattopadhyay, G., "Life cycle management for railway bridge assets", Proceedings of the Institution of Mechanical Engineers, Part F: Journal of Rail and Rapid Transit, 227 (5), pp. 570-581, 2013.

[Nour et al., 2016] Nour, S.I., Issa, M.A., "High speed rail short bridge-track-train interaction based on the decoupled equations of motion in the finite element domain", 2016 Joint Rail Conference, JRC 2016, 2016.

[Ntotsios et al., 2009] Ntotsios, E., Papadimitriou, C., Panetsos, P., Karaiskos, G., Perros, K., Perdikaris, P.C., "Bridge health monitoring system based on vibration measurements", Bulletin of Earthquake Engineering, 7 (2), pp. 469-483, 2009.

[ORR, 2015] Office of Rail and Road, "Passenger Rail Usage 2015-16 Q1 Statistical Release", statistical release, 2015.

[Ou, 2003] Ou, J. P., "Some recent advances of structural health monitoring systems for civil infrastructure in mainland China", Proceeding of the $1^{\text {st }}$ International Conference on Structural Health Monitoring and Intelligent Infrastructure, Tokyo, Japan, pp. 131-44, 2003.

[Park et al., 2009] J.H. Park, J.T. Kim, D.S. Honga, D.D. Hoa, J.H. Yib, “Sequential damage detection approaches for beams using time-modal features and artificial neural networks", Journal of Sound and Vibration, 323, 451-474, 2009.

[Pearl, 1986] Pearl, J., "Fusion, propagation, and structuring in belief networks", Artificial Intelligence, 29 (3), pp. 241-288, 1986.

[Phares et al., 2001] Phares, B.M., Graybeal, B.A., Rolander, D.D., Moore, M.E., Washer, G.A., "Reliability and accuracy of routine inspection of highway bridges", Transportation Research Record, (1749), pp. 82-92, 2001.

[Phares et al., 2004] Phares, B. M., Washer, G. A., Rolander, D. D., Graybeal, B. A. Moore, M., "Routine highway bridge inspection condition documentation accuracy and reliability", Journal of Bridge Engineering, 9 (4), pp. 403-13, 2004.

[Pipinato et al., 2016] A. Pipinato and R. Patton, "Chapter 19 - Railway bridges", In Innovative Bridge Design Handbook, Butterworth-Heinemann, Boston, pp. 509-527, ISBN 9780128000588, 2016.

[Polishchuk et al., 2015] Polishchuk, L.K., Kharchenko, H.V., Zvirko, O.I., "Corrosionfatigue crack-growth resistance of steel of the boom of a clamp-forming machine", Materials Science, 51 (2), pp. 229-234, 2015.

[Psimoulis et al., 2013] Psimoulis, P.A., Stiros, S.C., "Measuring deflections of a shortspan railway bridge using a robotic total station", Journal of Bridge Engineering, 18 (2), pp. 182-185, 2013.

[Qin, 2012] Qin, S.J., "Survey on data-driven industrial process monitoring and diagnosis", Annual Reviews in Control, 36 (2), pp. 220-234, 2012.

[Rafiq et al., 2015] Rafiq, M.I., Chryssanthopoulos, M.K., Sathananthan, S., "Bridge condition modelling and prediction using dynamic Bayesian belief networks", Structure and Infrastructure Engineering, 11 (1), pp. 38-50, 2015.

[Ren et al., 2013] Ren, J.-Y., Su, M.-B., Zeng, Q.-Y., "Railway simply supported steel truss bridge damage identification based on deflection", Information Technology Journal, 12 (17), pp. 3946-3951, 2013. 
[Reyer et al., 2011] Reyer, M., Hurlebaus, S., Mander, J., Ozbulut, O.E., “Design of a wireless sensor network for structural health monitoring of bridges", Proceedings of the International Conference on Sensing Technology, ICST, art. no. 6137033, pp. 515-520, 2011.

[Rigamonti et al., 2016] Rigamonti, M., Baraldi, P., Zio, E., Alessi, A., Astigarraga, D., Galarza, A., "Identification of the degradation state for condition-based maintenance of insulated gate bipolar transistors: A self-organizing map approach", Microelectronics Reliability, 60, pp. 48-61, 2016.

[Roberts et al., 2001] Roberts, G. W., Meng, X., and Dodson, A. H., "The use of kinematic GPS and triaxial accelerometers to monitor the deflections of large bridges" Proc., Deformation Measurements and Analysis, 10th Symposium on Deformation Measurements, Orange, California, 2001.

[Roberts et al., 2004] Roberts, G.W., Meng, X., Dodson, A.H., "Integrating a global positioning system and accelerometers to monitor the deflection of bridges", Journal of Surveying Engineering, 130 (2), pp. 65-72, 2004.

[Rocha et al., 2012] Rocha, J.M., Henriques, A.A., Calçada, R., "Safety assessment of a short span railway bridge for high-speed traffic using simulation techniques", Engineering Structures, 40, pp. 141-154, 2012.

[Rocha et al., 2016] Rocha, J.M., Henriques, A.A., Calçada, R., "Probabilistic assessment of the train running safety on a short-span high-speed railway bridge", Structure and Infrastructure Engineering, 12 (1), pp. 78-92, 2016.

[Sahlin et al., 2015] Sahlin, U., Di Maio, F., Vagnoli, M., Zio, E., "Evaluating the impact of climate change on the risk assessment of Nuclear Power Plants", Proceedings of the 25th European Safety and Reliability Conference, ESREL 2015, pp. 2613-2621, 2015. [Salamatian et al., 2013] Salamatian, S.A., Zarrati, A.R., Banazadeh, M., "Assessment of bridge safety due to scour by Bayesian network", Proceedings of the Institution of Civil Engineers: Water Management, 166 (6), pp. 341-350, 2013.

[Sanayei et al., 2015] Sanayei, M., Khaloo, A., Gul, M., Necati Catbas, F., "Automated finite element model updating of a scale bridge model using measured static and modal test data", Engineering Structures, 102, pp. 66-79, 2015.

[Santillán et al., 2015] Santillán, D., Salete, E., Toledo, M.Á., “A methodology for the assessment of the effect of climate change on the thermal-strain-stress behaviour of structures", Engineering Structures, 92, pp. 123-141, 2015.

[Santos et al., 2016] de Oliveira Dias Prudente dos Santos, J.P., Crémona, C., da Silveira, A.P.C., de Oliveira Martins, L.C., "Real-time damage detection based on pattern recognition", Structural Concrete, Article in Press, 2016.

[Sathananthan et al., 2010] Sathananthan, S., Onoufriou, T., Rafiq, M.I., "A risk ranking strategy for network level bridge management", Structure and Infrastructure Engineering, 6 (6), pp. 767-776, 2010.

[Schlune et al., 2009] Schlune, H., Plos, M., Gylltoft, K., "Improved bridge evaluation through finite element model updating using static and dynamic measurements", Engineering Structures, 31 (7), pp. 1477-1485, 2009.

[Sekuła et al., 2012] Sekuła, K., Kołakowski, P., "Piezo-based weigh-in-motion system for the railway transport", Structural Control and Health Monitoring, 19 (2), pp. 199-215, 2012.

[Shabbir et al., 2016] Shabbir, F., Omenzetter, P., "Model updating using genetic algorithms with sequential niche technique", Engineering Structures, 120, pp. 166-182, 2016. 
[Sharma et al., 2014] Sharma, K., Kumawat, J., Maheshwari, S., Jain, N., "Railway Security System based on Wireless Sensor Networks: State of the Art", International Journal of Computer, Applications, Volume 96- No.25, 2014.

[Shu et al., 2013] Shu, J., Zhang, Z., Gonzalez, I., Karoumi, R., "The application of a damage detection method using Artificial Neural Network and train-induced vibrations on a simplified railway bridge model", Engineering Structures, 52, pp. 408-421, 2013. [Silva et al., 2016] Silva, M., Santos, A., Figueiredo, E., Santos, R., Sales, C., Costa, J.C.W.A., "A novel unsupervised approach based on a genetic algorithm for structural damage detection in bridges", Engineering Applications of Artificial Intelligence, 52, pp. 168-180, 2016.

[Simoen et al., 2015] Simoen, E., De Roeck, G., Lombaert, G., "Dealing with uncertainty in model updating for damage assessment: A review", Mechanical Systems and Signal Processing, 56, pp. 123-149, 2015.

[Soyoz et al., 2009] Soyoz, S., Feng, M.Q., "Long-term monitoring and identification of bridge structural parameters", Computer-Aided Civil and Infrastructure Engineering, 24 (2), pp. 82-92, 2009.

[Specht, 1990] Specht, D.F., "Probabilistic neural networks", Neural Networks, 3 (1), pp. 109-118, 1990.

[Stajano et al., 2010] Stajano, F., Hoult, N., Wassell, I., Bennett, P., Middleton, C., Soga, K., "Smart bridges, smart tunnels: Transforming wireless sensor networks from research prototypes into robust engineering infrastructure", Ad Hoc Networks, 8 (8), pp. 872-888, 2010.

[Straub, 2009] Straub, D., "Stochastic Modelling of deterioration processes through Dynamic Bayesian Networks", Journal of Engineering Mechanics, pp. 1089-1099, 2009. [Sun et al., 2015] Sun, Z., Krishnan, S., Hackmann, G., Yan, G., Dyke, S.J., Lu, C., Irfanoglu, A., "Damage detection on a full-scale highway sign structure with a distributed wireless sensor network", Smart Structures and Systems, 16 (1), pp. 223-242, 2015. [Tantele et al., 2009] Tantele, E.A., Onoufriou, T., "Optimum preventative maintenance strategies using genetic algorithms and Bayesian updating", Ships and Offshore Structures, 4 (3), pp. 299-306, 2009.

[Tantele et al., 2010] Tantele, E.A., Onoufriou, T., "Optimization of life-cycle preventative maintenance strategies using genetic algorithm and Bayesian Updating", Bridge

Maintenance, Safety, Management and Life-Cycle Optimization - Proceedings of the 5th International Conference on Bridge Maintenance, Safety and Management, pp. 1603-1610, 2010.

[Teughels et al., 2002] Teughels, A., Maeck, J., De Roeck, G., "Damage assessment by FE model updating using damage functions", Computers and Structures, 80 (25), pp. 18691879, 2002.

[Vardanega et al., 2016] Vardanega, P.J., Webb, G.T., Fidler, P.R.A., Middleton, C.R., "Assessing the potential value of bridge monitoring systems", Proceedings of the Institution of Civil Engineers: Bridge Engineering, 169 (2), pp. 126-138, 2016.

[Venkatasubramanian et al., 2003] Venkatasubramanian, V., Rengaswamy, R., Yin, K., Kavuri, S.N., "A review of process fault detection and diagnosis part I: Quantitative model-based methods", Computers and Chemical Engineering, 27 (3), pp. 293-311, 2003. [Venkatasubramanian et al., 2003a] Venkatasubramanian, V., Rengaswamy, R., Kavuri, S.N., Yin, K., "A review of process fault detection and diagnosis part III: Process history based methods", Computers and Chemical Engineering, 27 (3), pp. 327-346, 2003. [Venkatasubramanian et al., 2003b] Venkatasubramanian, V., Rengaswamy, R., Kavuri, S.N., "A review of process fault detection and diagnosis part II: Qualitative models and search strategies", Computers and Chemical Engineering, 27 (3), pp. 313-326, 2003. 
[Wang et al., 2009] Wang, L., Chan, T.H.T., "Review of vibration-based fault detection and condition assessment of bridge structures using structural health monitoring", the Second Infrastructure Theme Postgraduate Conference, Queensland University, 2009. [Wang et al., 2012] Wang, R., Ma, L., Yan, C., Mathew, J., "Condition deterioration prediction of bridge elements using Dynamic Bayesian Networks (DBNs)", ICQR2MSE 2012, art. no. 6246298, pp. 566-571, 2012.

[Webb et al., 2015] Webb, G.T., Vardanega, P.J., Middleton, C.R., "Categories of SHM deployments: Technologies and capabilities", Journal of Bridge Engineering, 20 (11), art. no. 04014118, 2015.

[Weber et al., 2003] Weber, P., Jouffe, L., "Reliability modelling with dynamic Bayesian networks", the 5th IFAC Symposium on Fault Detection, Supervision and Safety of Technical Processes, Washington D.C, 2003.

[Wellalage et al., 2015] Wellalage, N.K.W., Zhang, T., Dwight, R., "Calibrating Markov chain-based deterioration models for predicting future conditions of railway bridge elements", Journal of Bridge Engineering, 20 (2), art. no. 04014060, 2015.

[Xia et al., 2006] Xia, Y., Hao, H., Zanardo, G., Deeks, A., "Long term vibration monitoring of an RC slab: Temperature and humidity effect", Engineering Structures, 28 (3), pp. 441-452, 2006.

[Xia et al., 2014] Xia, C., De Roeck, G., "Modal analysis of the Jalon Viaduct using FE updating", Proceedings of the International Conference on Structural Dynamic , EURODYN, 2014-January, pp. 2311-2317, 2014.

[Xie et al., 2011] Xie, H., Wang, Y., Liu, M., "Influences of climate change on reliability of bridge superstructure", Applied Mechanics and Materials, 94-96, pp. 1549-1555, 2011. [Yan et al., 2015] Yan, B., Dai, G.-L., Hu, N., "Recent development of design and construction of short span high-speed railway bridges in China", Engineering Structures, 100, pp. 707-717, 2015.

[Yan et al., 2016] Yan, R., Ma, Z., Kokogiannakis, G., Zhao, Y., "A sensor fault detection strategy for air handling units using cluster analysis", Automation in Construction, 70, pp. 77-88, 2016.

[Yeung et al., 2005] Yeung, W.T., Smith, J.W., "Fault detection in bridges using neural networks for pattern recognition of vibration signatures", Engineering Structures, 27 (5), pp. 685-698, 2005.

[Yi et al., 2013] Yi, T.-H., Li, H.-N., Gu, M., "Experimental assessment of high-rate GPS receivers for deformation monitoring of bridge", Measurement: Journal of the International Measurement Confederation, 46 (1), pp. 420-432, 2013.

[Yin et al., 2014] Yin, S., Ding, S.X., Xie, X., Luo, H., "A review on basic data-driven approaches for industrial process monitoring", IEEE Transactions on Industrial Electronics, 61 (11), art. no. 6717991, pp. 6414-6428, 2014.

[Zhan et al., 2011] Zhan, J.W., Xia, H., Chen, S.Y., De Roeck, G., "Structural damage identification for railway bridges based on train-induced bridge responses and sensitivity analysis", Journal of Sound and Vibration, 330 (4), pp. 757-770, 2011.

[Zhao et al., 2015] Zhao, X., Liu, H., Yu, Y., Xu, X., Hu, W., Li, M., Ou, J., “Bridge displacement monitoring method based on laser projection-sensing technology", Sensors, 15 (4), pp. 8444-8643, 2015.

[Zhong et al., 2014] Zhong, R., Zong, Z., Niu, J., Yuan, S., “A damage prognosis method of girder structures based on wavelet neural networks", Mathematical Problems in Engineering, 2014, art. no. 130274, 2014.

[Zhou \& Yi, 2014] Zhou, G.-D., Yi, T.-H., “A summary review of correlations between temperatures and vibration properties of long-span bridges", Mathematical Problems in Engineering, 2014, art. no. 638209, 2014. 
[Zhou et al., 2014] Zhou, X.T., Ni, Y.Q., Zhang, F.L., "Damage localization of cablesupported bridges using modal frequency data and probabilistic neural network", Mathematical Problems in Engineering, 2014, art. no. 837963, 2014.

[Zio et al., 2010] Zio, E., Di Maio, F., "A data-driven fuzzy approach for predicting the remaining useful life in dynamic failure scenarios of a nuclear system", Reliability Engineering and System Safety, 95 (1), pp. 49-57, 2010.

[Zio, 2012] Zio, E., "Prognostic and health management of industrial equipment", Diagnostic and Prognostic of Engineering Systems: Methods and Techniques, IGI Global, pp. 333-356, 2012.

[Zio, 2016] Zio, E., "Challenges in the vulnerability and risk analysis of critical infrastructures", Reliability Engineering and System Safety, 152, pp. 137-150, 2016. [Zonta et al., 2007] Zonta, D., Pozzi, M., Zanon, P., "Bayesian approach to condition monitoring of PRC bridges”, Key Engineering Materials, 347, pp. 227-232, 2007. 